\title{
EN TORNO AL RETABLO MAYOR DEL MONASTERIO DE SAN JERÓNIMO DE GRANADA: SUS ARTÍFICES, PROCESO CONSTRUCTIVO, ICONOGRAFÍA Y MODELOS VISUALES
}

\author{
POR \\ José Policarpo Cruz CABRERA ${ }^{1}$ \\ Universidad de Granada
}

\begin{abstract}
RESUMEN
El retablo mayor de San Jerónimo de Granada constituye sin duda alguna una de las piezas señeras de la retablística andaluza e hispana de la Edad Moderna, tanto por la impronta clasicista de su arquitectura como por la confluencia de diversos maestros en la transición del renacimiento al primer naturalismo seiscentista. El artículo ofrece un estado de la cuestión sobre sus posibles autores, profundiza en su historia constructiva y aspectos iconográficos y, finalmente, aporta una visión inédita sobre las fuentes visuales que sirvieron de inspiración a esta magna obra.
\end{abstract}

PALABRAS CLAVE: Granada; monasterio de San Jerónimo; escultura renacentista; fuentes; grabados.

\section{THE MAIN ALTARPIECE OF SAINT JEROME MONASTERY IN GRANADA: AUTHORS, BUILDING PROCESS, ICONOGRAPHY AND VISUAL PATTERNS}

\begin{abstract}
The main altarpiece of Saint Jerome in Granada undoubtedly ranks among the most outstanding examples of altarpiece artistry in modern age Spain and Andalusia. This is due to the classicistic mark of its architecture as well as to the cooperation of different maestros over the transition period from the Renaissance to the early naturalism of the17th century. This paper offers a state-of-the-art debate over the issue of the altarpiece authors, an insight on its iconography and construction process as well as an original interpretation of the visual elements that inspired this masterpiece.
\end{abstract}

KEY WORDS: Granada; Saint Jerome monastery; Renaissance sculpture; sources; engravings.

Cómo CitAR eSte ARTículo / CitATION: Cruz Cabrera, J. P. 2017. «En torno al retablo mayor del monasterio de San Jerónimo de Granada: sus artífices, proceso constructivo, iconografía y modelos visuales». Hispania Sacra 69, 139: 163-176. doi: 10.3989/ hs.2017.011

Recibido/Received 26-09-2014

Aceptado/Accepted $\quad$ 01-02-2016

\section{El Real Monasterio de SAN Jerónimo}

La ciudad de Granada, tras la conquista de 1492, estuvo destinada a convertirse en uno de los centros fundamentales del renacimiento hispano. Con su incorporación a Castilla se fundieron el simbolismo religioso propio de una cruzada tardomedieval con los intereses políticos y dinásticos de los Reyes Católicos en la configuración del Estado Moderno. De hecho la importancia ideológica y geoestratégica

\footnotetext{
1 jcruz@ugr.es / ORCID iD: http://orcid.org/0000-0003-1306-8365
}

de esta anexión determinó que la ciudad pasase a ser durante la primera mitad del Quinientos un proyecto cortesano singular, símbolo material del nuevo orden de cosas instaurado por la monarquía autoritaria de aquellos monarcas y de su sucesor, don Carlos V.

De esta forma, vivió un periodo de esplendor durante las primeras décadas del siglo XVI. Amén de ser incluida en la lista de 18 ciudades de la Corona con voto en Cortes quedó, en 1500, como cabeza de un concejo municipal de amplísima jurisdicción -comprendía la Vega, Alpujarras y Costa-. Además, fue instituida su sede catedralicia metropolitana como modelo de un marcado intervencionismo estatal a 
tenor del Patronato Real erigido en 1486, que permitía a los monarcas la elección de su arzobispo. También adquirió un estatus militar específico -banco de pruebas para los virreinatos coloniales- con la creación de la Capitanía General del Reino de Granada, bajo el mando de los marqueses de Mondéjar, alcaides de la Alhambra. Y fue asimismo sede judicial y cultural con la creación de la Real Chancillería de Granada (1506) y de la Universidad carolina (1531), respectivamente.

La imagen de Granada como ciudad cortesana culminaría con dos grandes empresas de alto valor simbólico interrelacionadas. En primer lugar, además de la fundación de la Real Capilla de los Reyes Católicos, el proyecto de convertir la capilla mayor catedralicia en panteón regio de los Austrias; y, en segundo lugar la construcción del Palacio de Carlos V junto a las Casas Reales Viejas de la Alhambra. ${ }^{2}$ La rotonda siloesca de la Catedral supondría un reflejo a nivel espiritual del patio circular del palatino a nivel político, imagen a su vez de la universitas christiana carolina. ${ }^{3}$

Ese sentido de capitalidad que los Reyes Católicos dieron a la ciudad se plasmó en una serie de fundaciones regias, quizás sólo comparables a las realizadas en la corte seiscentista madrileña: la mentada Capilla Real, el Hospital Real, la Chancillería y las fundaciones regulares de las Comendadoras de Santiago, Santa Isabel la Real, San Francisco Casa-Grande, Mercedarios Calzados, Santa Cruz la Real y San Jerónimo.

Este último monasterio, a cuya orden pertenecía el confesor regio y primer arzobispo de Granada, fray Hernando de Talavera, se erigió en 1492 en el campamento de Santa Fe, bajo la advocación de Santa Catalina Mártir. Poco después se trasladó a Granada, con el título de monasterio de la Concepción de Nuestra Señora, estableciéndose sobre una almunia regia en el solar que hoy ocupa el vecino hospital de San Juan de Dios. Consta que en 1496 ya se hacían allí trabajos de edificación, para los cuales los Reyes Católicos cedieron, en 1500, material de acarreo procedente de la Puerta de Elvira.

Sin embargo, en 1504 se dispuso pasase la fundación a su actual emplazamiento, en el que se trabajaría febrilmente hasta la terminación, en 1519, del claustro principal, mudándose allí los monjes dos años después. Por su parte, aunque las obras de la iglesia se iniciaron en 1513, se avanzó poco en los seis años siguientes, de forma que, en 1523 estaban hechos los muros perimetrales hasta el cerramiento de las capillas hornacinas. ${ }^{4}$ Estos trabajos se asentaron sobre una fuerte asignación de rentas, ${ }^{5}$ lo que da una cabal idea del interés personal que el arzobispo Talavera y los monarcas tuvieron sobre la fundación jerónima, que tendría un marcado protagonismo urbano en la entrada principal de

\footnotetext{
2 Véase, sobre la configuración de Granada como centro eclesiástico, militar, judicial, cultural, docente, simbólico y cortesano, en su relación con las artes: Cruz Cabrera 2010.

3 Bustamante García y Marías Franco 1982.

4 El conjunto de San Jerónimo ha sido muy estudiado por la historiografía hispana en el contexto de la arquitectura renacentista. A nivel monográfico véanse: Gómez-Moreno González 1892; Valladar y Serrano 1906; Colina Munguía 1986; Gallego Burín 1996: 284-294; Espinar Moreno y García Ruiz 2003; Anguita Cantero, Cruz Cabrera y GómezMoreno Calera 2006: 115-133; Gutiérrez García 2007 y Martínez y Curiel 2011.

5 Marín López 1999.
}

la ciudad, junto con el imponente buque arquitectónico del hospital regio.

Clara muestra del cuidado puesto en la empresa es el plan arquitectónico inspirado en la Capilla Real bajo la dirección de Enrique Egas (circa 1455-1534) y en la fundación dominica de Santa Cruz la Real: ${ }^{6}$ iglesia conventual de una nave, con capillas hornacinas, coro alto a los pies, crucero y presbiterio sobreelevado con pequeñas capillas en sus ángulos. Es por tanto plausible la intervención de Egas en las fases iniciales de la obra. De lo que no hay duda es que este modelo, a mayor escala en el edificio jerónimo que en el citado panteón regio, condicionaría sin duda alguna la historia posterior del edificio como conjunto alta representatividad (Fig. 1).

\section{FIGURA 1}

Iglesia del monasterio de San Jerónimo de Granada. Foto: José Manuel Gómez-Moreno Calera

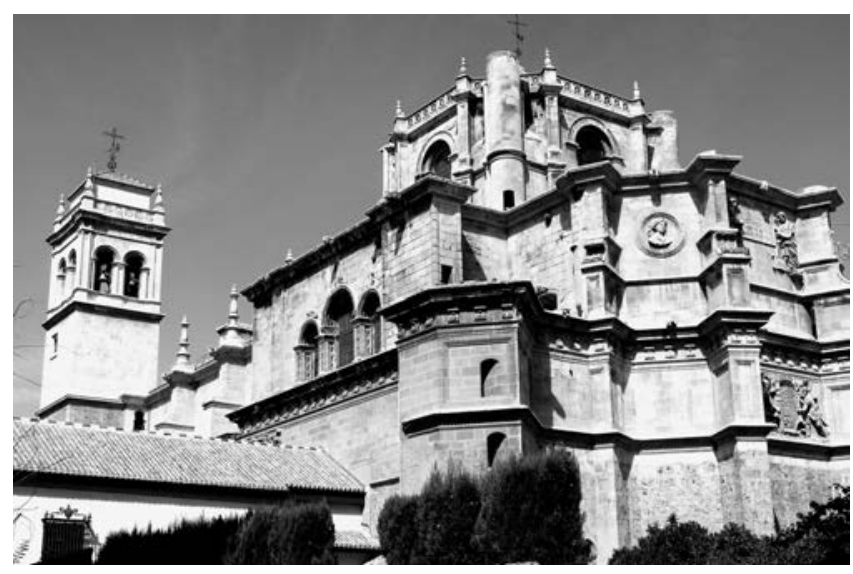

\section{LA CAPILLA MAYOR: PANTEÓN DEL GRAN CAPITÁN}

En 1523 se produjo un hecho excepcional para las obras de la iglesia y la conversión del edificio en una magna muestra del renacimiento hispano: doña María Manrique, duquesa de Sesa y Terranova y viuda del Gran Capitán, solicitó y obtuvo del monarca Carlos V la cesión de la capilla mayor para enterramiento de su marido y descendientes. Ello derivó en una escritura de patronato concertada en 1525, y que supuso la intervención de Jacobo Florentino "El Indaco" (1476-1526) en las obras, bajo cuya dirección la capilla mayor daría un giro radical: se dejó de lado el austero modelo goticista propio de la Capilla Real por una nueva arquitectura triunfalista a lo romano ejemplificada en los grandes pilares torales de orden corintio por él diseñados.

Con la intervención posterior de Diego de Siloé (14951563) este noble panteón alcanzaría inusitadas cotas de monumentalidad. En palabras del gran cronista de la orden, fray José de Sigüenza: «A la hermosura del claustro y cuerpo de la iglesia se le añadió la capilla mayor, que sin hacer agravio a todo lo de aquel tiempo y aún a lo mejor de éste (siempre se excepta San Lorenzo el Real) es lo mejor de

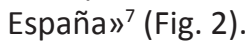

\footnotetext{
6 Véanse, al respecto las reflexiones de Caballero Escamilla 2014. José de Sigüenza 1605: 47-54. Derrocha el autor elogios a la intervención de Siloé, sin nombrar ningún otro maestro.
} 
FIGURA 2

Capilla mayor del monasterio de San Jerónimo de Granada, panteón del Gran Capitán. Foto: José Manuel Gómez-Moreno Calera

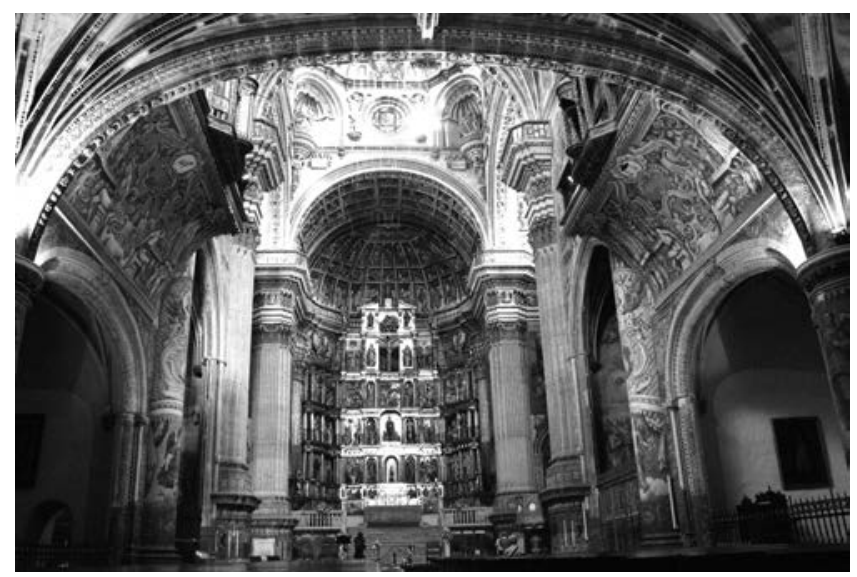

Es difícil saber con certeza cuánto del diseño de este panteón humanista -modelo en cierto modo de otras grandes propuestas del renacimiento andaluz, como la Sacra Capilla del Salvador de Úbeda y la capilla mayor de San Francisco de Baeza-, se debería a aquel artífice italiano, dado que falleció en Granada en enero de 1526. Y, por tanto, cuánto se debe al gran maestro Diego de Siloé, que vino a la ciudad en marzo de 1528 para continuar las obras, con un contrato de 300 ducados anuales y estancia.

Se acepta desde Gómez-Moreno en adelante que Siloé continuaría los trabajos del florentino a partir del entablamento de la cabecera, por lo que cabe suponer que habría comenzado las obras bastante antes de la escritura de cesión de la capilla por Real Cédula de 27 de marzo de $1523 .{ }^{8}$

Sin embargo, para Carrasco de Jaime la intervención del Indaco debió ser muy determinante, pues seguramente las obras de la capilla mayor podrían haber empezado bastante antes, desde al menos 1520, según trazas del maestro florentino, de forma ilícita y bajo el consentimiento de los monjes. Esta opinión se basa en ciertos términos usados en la mencionada escritura, en alusión a la duquesa de Sesa y cómo "fue hecha relación que vos quería desacallar de edificar la capilla mayor de la iglesia del dicho monasterio de San Jerónimo de la dicha ciudad de Granada, que está comenzada a labrar». Idea parecida se refleja, en cierto modo, en la escritura de patronato realizada en 1525:

Ytem que la dicha señora duquesa hará labrar y hacer la capilla mayor de la iglesia del dicho monasterio con todo el pilar gordo y sus tijeras y ferreal, por cuanto todo ello, con el púlpito que se ha de quedar dentro de la reja de la dicha capilla, si la dicha señora quisiere; y asimismo que su señoría hará hacer el retablo y reja que en ella se ha de poner. $^{9}$

8 Gómez-Moreno González, M. 1892: 362, 377; Marías Franco 1989.

9 Carrasco de Jaime 2007. Los entrecomillados (p. 392) proceden del Libro Becerro de la fundación, conservado en la sección Clero del Archivo Histórico Nacional (Libro 3692, fols. 86-113). Marías Franco, F. (1989: 367) también afirma la presencia de un maestro italiano en las obras hacia 1519, habiéndose negado a realizar los sepulcros del panteón tanto Miguel Ángel como Andrea Sansovino.
Sea como fuere, el maestro burgalés confirió su sello personal al conjunto, y no sólo a la capilla mayor, al trabajar tanto para los duques de Sesa en dicho espacio como para los monjes en las obras de la iglesia, sillería de coro y alhajamiento de las portadas de las capillas funerarias del claustro. En ello, lógicamente, tendría mucho que ver la voluntad del jerónimo fray Pedro Ramiro de Alva -su lauda sepulcral, atribuida a Siloé, se conserva en una de las dependencias del monasterio granadino-, a la sazón arzobispo de Granada y por tanto supervisor de la otra gran empresa arquitectónica siloesca de la ciudad: el templo catedralicio.

Para la capilla mayor se admite sin género de dudas la mano de Siloé a partir de los frisos. Por tanto, es el responsable del espléndido programa iconográfico de signo humanista de los casetones del crucero, donde hombres y mujeres ilustres de la antigüedad, en christiana concordatio con santos y santas, pregonan las glorias del Gran Capitán y su esposa. ${ }^{10}$

Siloé trabajó en el noble panteón desde el 20 de abril de 1528 hasta el 22 de marzo de 1543, cuando quedó concluida la obra. Perdió entonces el artista el favor del comitente, llegándose a un conflicto judicial que se dio por zanjado con el despido del artista el 10 de enero de 1548 por parte del tercer duque de Sesa, don Gonzalo Fernández de Córdoba. Quizás en la raíz del conflicto radicaba el hecho de que éste libró 347.398 maravedís frente a los 386.819 que le demandaba el artífice. ${ }^{11}$ Por otro lado, no era extraño en la época que los herederos de los mecenas fuesen perdiendo paulatinamente interés por aquellos grandes patronazgos que les suponían una considerable merma en sus rentas en momentos de necesidad. ${ }^{12}$

La importancia de esta cuestión para el tema que nos ocupa es que tras cinco años de tensiones, al ser despedido oficialmente Siloé, no pudo llevarse por completo a cabo lo prevenido en el contrato de 1528. A tenor del mismo, el artista se comprometía a que «la capilla de San Jerónimo de Granada se ha de labrar a lo romano, como se ha comenzado, hasta acabarse», mientras que Juan Franco, contador de los duques, prometía «que el retablo de la dicha capilla lo hará el dicho Diego de Siloé y no otra persona». ${ }^{13}$ 2008

Véase al respecto la siguiente tesis doctoral: Callejón Peláez

11 Romero Martínez 1999. La autora transcribe tanto la carta de despido firmada por el duque como la queja formulada por Siloé ante el alcalde mayor de Granada, que forman parte de un expediente del siglo XVIII conservado en el Archivo Histórico Provincial de Granada (Leg. 205-2576-1), copia a su vez del pleito original entre ambos, transcrito en parte por los Gómez-Moreno y guardado en el Archivo de la Real Chancillería de Granada (Leg. 321-4341-29).

12 Un buen ejemplo de ello es la capilla mayor de don Valencia de Benavides en el convento de San Francisco de Baeza, en gran medida inspirada en el panteón del Gran Capitán. Muerto el fundador a los pocos meses de firmar la escritura de patronato, de 1538, su sucesor, don Diego Valencia de Benavides, se negó a cumplir el testamento de su padre, lo que obligó a los frailes a interponer un pleito. Tras ganarlo, Andrés de Vandelvira se encargaría de levantar la capilla entre 1540 y 1546. Cruz Cabrera 1999.

13 Gómez-Moreno Martínez 1983: 182-183. Tomado del contrato firmado por Diego de Siloé en 20 de abril de 1528, conservado en los fondos del Archivo Histórico Provincial de Granada, sección Hacienda. 


\section{EL RETABLO MAYOR (1576-1603)}

La mención a la construcción del retablo, reja y sepulcros en documentos citados de 1525, 1528, 1543 y 1548 sugiere que se tenía una idea muy clara del tipo de maquinaria con que se quería dotar a la capilla mayor. Es posible incluso que circulasen proyectos o trazas que no llegarían a materializarse, quizás de la mano de Florentino o del propio Siloé. La reja finalmente fue obra de Francisco de Aguilar, de 1601, aunque lamentablemente se perdió durante la invasión napoleónica de 1808. Los sepulcros exentos ideados en un principio para el centro de la capilla mayor, como los célebres mausoleos de la Capilla Real, no llegaron a realizarse, si bien hubo un proyecto de transformar el espacio funerario como trasunto de El Escorial y según el decoro impuesto por la norma contrarreformista, que finalmente no se llevó a efecto. ${ }^{14}$

FIGURA 3

Retablo mayor de San Jerónimo de Granada (1576-1603). Foto: José Carlos Madero López

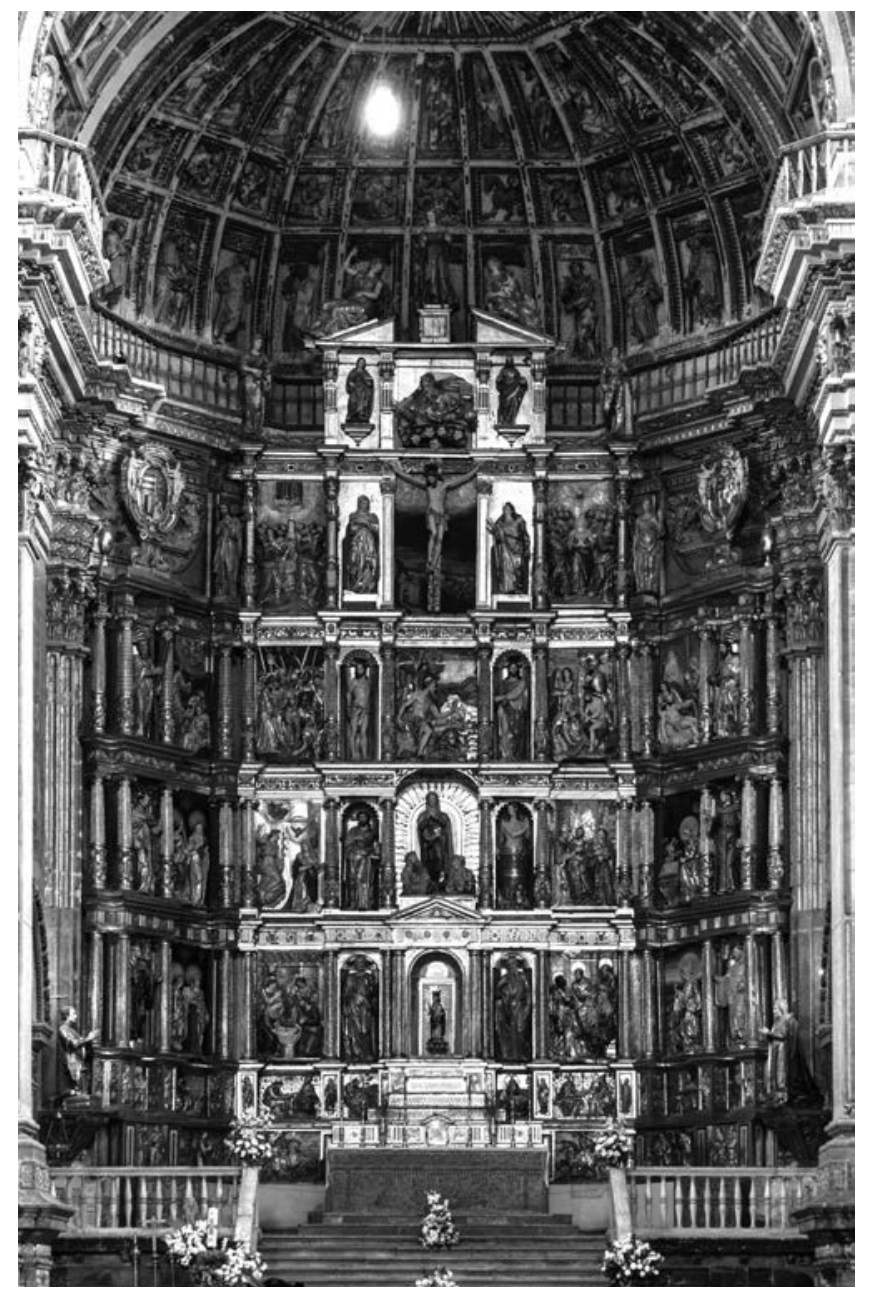

14 Bustamante Garcia 1995: 17. Recoge el autor el interés puesto en ello por el sexto duque de Sesa, don Luis Fernández de Córdoba, quien dio órdenes a Gaspar de Bilbao para reconocer el sitio en 1622, y cuyo parecer fue que la bóveda de la cripta era demasiado pequeña y difícil de modificar sin mucho coste, por lo que estimaba que lo mejor era poner los cuerpos en los nichos de las capillas colaterales. Juan Gómez de Mora realizó algunos proyectos a tal efecto que no se llegaron finalmente a ejecutar.
En cambio, y aunque también con retraso, el retablo mayor sí se realizó y se conserva hoy día primorosamente (Fig. 3). Se inició bastante después de la terminación de las obras, a partir de 1576, y su construcción duró unos 27 años. Sin embargo, el esfuerzo valió plenamente la pena, como afirma Bustamante García, por ser:

..obra de gran calidad en el punto de arranque de la transformación del retablo granadino por lo que respecta al ensamblaje, gracias a una nueva concepción disciplinada de su estructura a través de los órdenes; y en cuanto a la escultura, con sus vínculos con las novedades sevillanas. ${ }^{15}$

En efecto, se trata de una grandiosa maquinaria, compuesta de sotabanco, banco, cuatro cuerpos y ático. Queda organizada en nueve calles separadas por columnas, las dos finales de cada lado quebradas, para adaptarse a la estructura ochavada del testero. La escultura es exenta en las calles extremas y en las que flanquean a la central -más estrechas, concebidas prácticamente como entrecalles-, amén del Calvario del cuarto cuerpo y santos a los lados del Padre Eterno, en el ático, mientras que los tableros en relieve se enseñorean en banco, sotabanco y calles restantes. Cuenta, además, con el añadido de esculturas alegóricas y de la heráldica de los mecenas en los remates, así como de sus imágenes orantes en las esquinas inferiores; todo ello, en una perfecta organización de órdenes arquitectónicos superpuestos y con una riquísima ornamentación cuidadosamente policromada en pedestales, basamentos y frisos.

El sotabanco lleva encasamientos rectangulares con relieves, separados por pedestales planos, los cuales parecen corresponder a los últimos momentos de ejecución del conjunto. Por su parte, el banco corresponde a las primeras fases de la obra, y queda organizado igualmente mediante relieves hagiográficos separados por pedestales que muestran santas mártires en sus frentes y guirnaldas de grutescos en sus laterales.

FIGURA 4

Sotabanco, banco y primer cuerpo del retablo. Foto: José Carlos Madero López

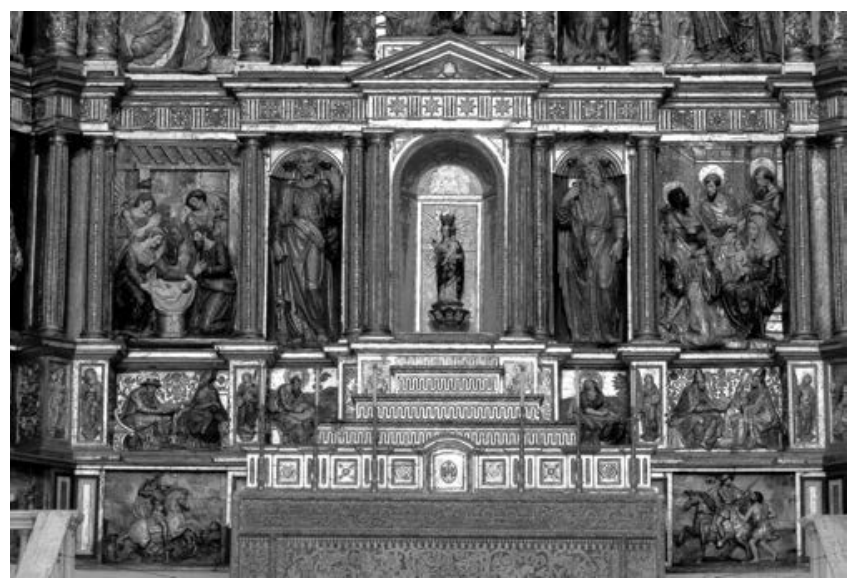

El primer cuerpo es dórico, con columnas acanaladas y friso de triglifos y metopas adornadas alternativamente con cabezas de angelitos y rosetas (Fig. 4). El segundo, es

\footnotetext{
15 Ibídem: 16.
} 
jónico, presentando las columnas en su imoscapo motivos tales como grutescos, putti, y figuras religiosas, al tiempo que el friso muestra guirnaldas de máscaras sostenidas por angelitos. El siguiente cuerpo, corintio, presenta fustes semejantes a los anteriores y un entablamento remetido en todas las calles, a diferencia de los de los otros dos, que ostentan un perfil más continuo (Fig. 5).

FIGURA 5

Segundo y tercer cuerpo del retablo. Foto: José Carlos Madero López

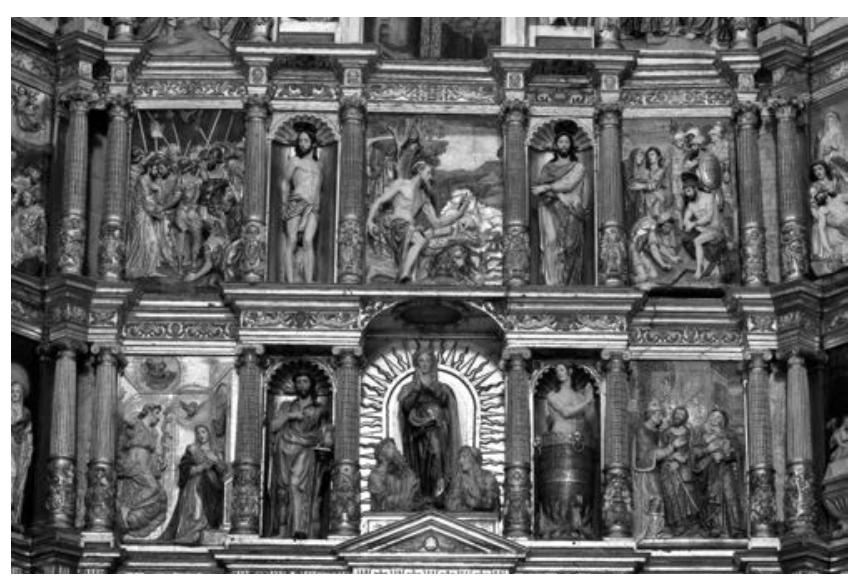

Sobre él, se eleva un cuarto cuerpo, añadido a principios del siglo XVII -como se verá seguidamente- y más estrecho que el resto del conjunto, pues sólo cuenta con cinco encasamientos que se corresponden con el fondo plano de la cabecera del templo. Su estructura es de mayor sobriedad, articulándose con pilastras compuestas las tres calles centrales, que albergan la Déesis, mientras los tableros extremos quedan flanqueados por columnas corintias de fuste liso, pero con relieves de amorcillos en su imoscapo y guirnaldas en el tercio superior. El ático es aún más sobrio, ya no presenta frisos decorativos y se articula mediante tres calles marcadas por pilastras manieristas con mutilos curvos y frontón partido que sustenta las Virtudes Teologales (Fig. 6).

FIGURA 6

Cuarto cuerpo y ático del retablo. Foto: José Carlos Madero López

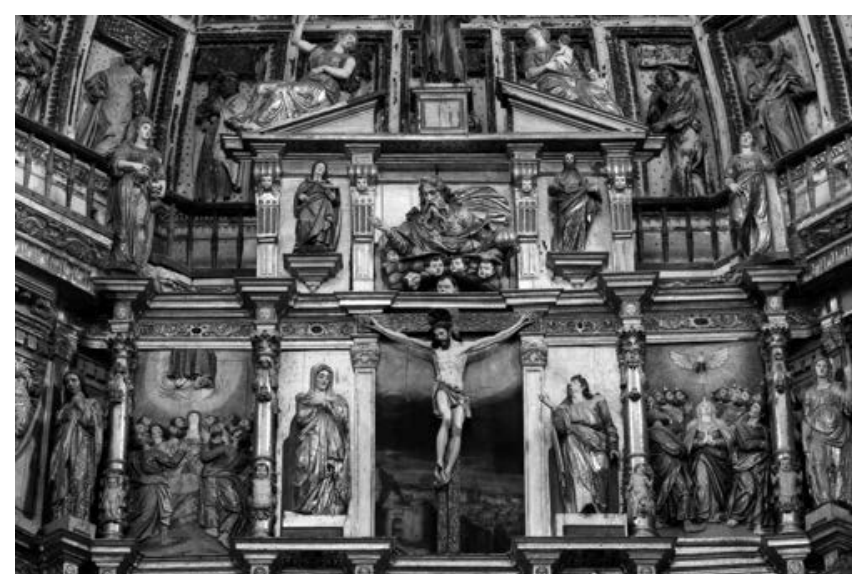

\section{Autores}

El retablo mayor de San Jerónimo es una obra muy compleja, debido a lo dilatado de su materialización (de 1576 a 1603), con varias modificaciones y diferentes maestros. Como pieza clave en el desarrollo de la retablística granadina, andaluza y aún hispana, ha sido ponderado por un gran número de investigadores, desde los GómezMoreno a Gallego Burín, Azcárate, Sánchez-Mesa, Henares Cuéllar, Bustamante García, Ulierte Vázquez, Hernández Díaz o Morales Martínez, entre otros. ${ }^{16}$

La progresiva materialización de esta insigne maquinaria fue dada a conocer primeramente por Gómez-Moreno González, arrancando de un primer contrato con el pintor Juan de Aragón (activo entre 1552 y 1594), en 1570, que tres años más tarde sería modificado bajo diseño de Lázaro de Velasco (circa 1520-1585), y, finalmente, ampliado en 1603 según trazas de Pedro de Orea, haciéndose cargo del ensamblaje de esta última fase Diego de Navas y de la pintura Pedro de Raxis (1555-1626). ${ }^{17}$ Por su parte, Gómez-Moreno Martínez fue quien asignó la obra a dos grupos de artífices: lo principal, más antiguo y meritorio al sevillano Juan Bautista Vázquez "El Mozo" (activo entre las décadas de 1570 y 1610) y al granadino Melchor de Turín o Torines -nacido hacia 1550 y formado con Juan Bautista Vázquez el Viejo (1510-1588), con el que trabajaría en el gran retablo de Santa María de Medina Sidonia-; por otro lado, lo ampliado correspondería al núcleo granadino de Bernabé de Gaviria (1577-1622) o Pablo de Rojas (1549-1611), argumentando, amén de las diferencias de ejecución, otras en materiales (nogal en el primer proyecto y pino en el segundo) y en el estofado. ${ }^{18}$

Más tarde, Gallego Burín, basándose en un manuscrito inédito de Gómez-Moreno González sobre la escultura granadina, vinculó erróneamente a Diego de Pesquera (circa 1540-1581) a esta obra como uno de los tracistas, y apuntó que la primera fase sería de Vázquez el Mozo y Rojas, asignando la segunda a Gaviria. ${ }^{19}$ Asimismo, identificó, siempre a tenor de las aportaciones de los Gómez-Moreno, las partes añadidas a principios del siglo XVII: todo el cuarto cuerpo con el ático, así como las siguientes obras:

16 Es muy abundante y prolija la bibliografía generada en torno al retablo de San Jerónimo, pero la mejor aproximación al mismo, recogiendo aportaciones anteriores, es el trabajo siguiente: Gómez-Moreno Calera 2010: en especial las páginas 249 a 254 . Corroboramos el texto del profesor Gómez-Moreno Calera en los aspectos históricos y de atribución, agradecemos públicamente sus consejos y comentarios al respecto y anotamos otras contribuciones en las sucesivas notas.

17 Los autores de esta intervención ya eran conocidos de antiguo: Ceán Bermúdez 1800. Pero el erudito apuntó el nombre de Diego de Navas como autor de todas las esculturas y del pintor Pedro de Uceda como tracista del conjunto. Gómez-Moreno González 1892: 387 transcribiría bien el nombre, cambiando Uceda por Orea. Véase: Salas 1967: 165 y 195.

18 Gómez-Moreno González 1892: $369-372$ y Gómez-Moreno Martínez 1931: 91.

19 Gallego Burín 1996: 291. El autor alude a un pleito mantenido por la tasación del retablo con la viuda de Juan de Aragón, realizando una nueva el arquitecto Asensio de Maeda, junto con los pintores Alonso Rivero de Jaén, Luis Fernández y Francisco Castillejo, de Sevilla y Miguel Sánchez, de Córdoba. No obstante, como nos ha aclarado el profesor Gómez-Moreno Calera, Gallego Burín no advirtió que estos datos correspondían en realidad al desaparecido retablo de la iglesia de Colomera (Granada), en el que sí participó el citado Diego de Pesquera, documentado en Sevilla por las fechas en que se trabajaba en el de San Jerónimo. 
los serafines bajo el Dios Padre, San Benito, San Bernardo -ambas en el primer cuerpo-, la Prudencia y San Justo, amén de los relieves del cuarto cuerpo -Pentecostés y Ascensión- además de los de la Adoración de los Pastores y Presentación de Jesús, en primer y segundo cuerpo, respectivamente, si bien San Benito y el citado relieve de la Adoración de los Pastores mostraban una mayor calidad. Por su parte, Sánchez-Mesa asignó a Vázquez el Mozo directamente los temas de la Anunciación, Epifanía, Circuncisión, San Juan Evangelista y San Juan Bautista, Ecce Homo y Cristo a la Columna, siendo lo demás, en su opinión, de Melchor de Turín, Pesquera y Rojas. ${ }^{20}$

La historiografía posterior ha recogido y aceptado estos datos, puntualizando algunas cuestiones. Así, Hernández Díaz dio a conocer la fecha correcta del contrato, no 1570, sino 1576 ( $y$, por consiguiente, siendo las trazas de Lázaro de Velasco de 1579), ratificando la atribución a Vázquez el Mozo y Turín para la primera fase y la personalidad de Rojas para la segunda; ${ }^{21}$ autorías éstas aceptadas sin reservas por la mayor parte de los autores, ${ }^{22}$ aunque algunos han sido más restrictivos con la intervención de este último maestro. ${ }^{23}$

Posteriormente se ha incorporado al capítulo de atribuciones alguna novedad en cuanto a la posible intervención de un enigmático Rodrigo Moreno, citado por el cronista Bermúdez de Pedraza en 1608 como «varón de monstruoso ingenio» en el arte de la escultura, ${ }^{24}$ al que la historiografía local vincula a trabajos escurialenses y como formador de Pablo de Rojas, aunque a día de hoy no se le ha podido reconocer obra alguna. ${ }^{25} \mathrm{~A}$ pesar de ello, es sugerente la alusión de Ceán Bermúdez acerca de cómo

...tuvo grandes créditos en aquella ciudad por los años de 1576, y el licenciado Bermúdez de Pedraza dice que presentó a Felipe II un excelente Crucifijo de su mano para el monasterio de El Escorial. Fue maestro de Pablo de Rojas y sus obras estarán en aquella ciudad atribuidas a otros profesores. ${ }^{26}$

20 Sánchez-Mesa Martín 1971: 95. La intervención de Pesquera es incorrecta, según lo comentado en nota anterior. Por otro lado, la asignación a Vázquez el Mozo de los relieves de la Epifanía y Circuncisión procede de Azcárate, si bien hay que aclarar que hay una confusión pues el tema de la Circuncisión no existe en el retablo, y sí el de la Presentación en el Templo: Azcárate Ristori 1958: 337.

${ }^{21}$ Hernández Díaz 1982. La confusión entre las fechas de 1570 y 1576 (en las notas manuscritas a la Guía de Granada de 1892 ya viene enmendado el error de transcripción) se ha seguido manteniendo, hasta haber sido aclarada definitivamente por Gómez-Moreno Calera 2010: 249.

22 Véanse, entre otros: Gallego Burín 1937: 20-21 y 24-25; GómezMoreno Rodríguez 1951: 101 y 119; Morales Martínez 1992: 208-211; Sánchez-Mesa Martín 1994: 65-67; Ulierte Vázquez 1994: 433-436.

${ }_{23}$ Bernales Ballesteros 1994: 189, restringe la participación de Vázquez a Jesús de la Columna, San Juan Evangelista y los relieves de la Anunciación, Epifania y Circuncisión (sic). El papel de Rojas lo vincula a la Ascensión y a la Adoración de los Pastores; sin duda alguna, por su relación formal con los temas homónimos desarrollados por Martínez Montañés en el grandioso retablo del monasterio de San Isidoro del Campo en Santiponce (Sevilla), que parecen confirmar la maestría del primero sobre el segundo, como han mencionado, entre otros, Gallego Burín, Gómez-Moreno Rodríguez, Hernández Díaz o Sánchez-Mesa.

${ }^{24}$ Bermúdez de Pedraza 1608. Fue Orozco Díaz el primero en sugerir la posible participación de este artífice en el retablo de San Jerónimo: Orozco Díaz 1972: 108. El profesor Gómez-Moreno Calera (2010: 251) recupera esta muy poco conocida hipótesis.

25 Sobre las escasas noticias en torno a este artífice, LópezGuadalupe Muñoz 2010: en especial 141.

26 Ceán Bermúdez 1800: T. III, 197.
Por nuestra parte, añadimos una doble reflexión: acaso el trabajo para los jerónimos de El Escorial y la mención a la fecha exacta de 1576 sean reflejo de su plausible intervención en el retablo que nos ocupa.

También cabe considerar la idea de que, para la reforma de 1603, hubiera trabajado Diego de Aranda, -hijo del artífice homónimo discípulo de Siloé- que suele aparecer en otras obras como colaborador del citado ensamblador Diego de Navas, como muy bien ha sugerido el profesor Gómez-Moreno Calera, ${ }^{27}$ lo cual podría confirmarse en los relieves citados más arriba, salvo en el de la Adoración de los Pastores, dado que en este caso la mayor calidad y el calado en la obra montañesina de Santiponce parecen certificar la autoría de Rojas.

Finalmente, se ha documentado cómo la efigie de la Inmaculada del segundo cuerpo es en realidad muy posterior:

...la imagen nueva que está en el altar mayor de Nuestra Señora de la Concepción, titular de este real templo, la hizo Antonio de Sala, natural de Valencia, labrada en la hospedería...; acabóse de hacer de madera el día 18 de marzo de 1697. La doró y estofó Gregorio de Rueda, vecino de esta ciudad. ${ }^{28}$

Hoy parece poco probable seguir avanzando más en lo referente a los posibles autores, dándose la circunstancia paradójica de que, desde el punto de vista documental, las referencias existentes muestran sucesivos contratos con maestros pintores, a quienes han de deberse los trabajos de trazas, pintura y dorado. Cabe suponer que tales artífices subcontratarían la obra con ensambladores e imagineros de los que, hasta el momento, no ha quedado huella escrita de su participación.

Por tanto, sólo consta documentalmente la intervención del pintor Juan de Aragón y de Lázaro de Velasco -éste únicamente como tracista- en 1576 y 1579, respectivamente, mientras que para la reforma de 1603 se nombra al arquitecto Pedro de Orea como tracista, a Pedro de Raxis como policromador ${ }^{29}$ y a Diego de Navas como ensamblador. ${ }^{30}$ La

27 Gómez-Moreno Calera 2010: 251. Así, por ejemplo, intervinieron Navas, Aranda, Rojas y Raxis en la hechura del desaparecido retablo de Nuestra Señora de la Antigua (1586), en la catedral granadina.

28 Martínez Justicia 1996: 49. La noticia la dio a conocer SánchezMesa Martín (1971: 96) y procede de un libro, hoy en paradero desconocido, que estuvo en el convento de Santa Paula de Granada. Apunta que la imagen original del retablo posiblemente sea una bella Inmaculada existente en la parroquia granadina de San Ildefonso, atribuida a Bautista Vázquez el Mozo.

${ }_{29}$ También se ha querido ver diferencias de ejecución entre las partes pintadas por Aragón y por Raxis. Para Martín González (1983: 186), lo primero "está cubierto de rutilantes oros, mientras que Raxis daba preferencia a las labores grabadas y pictóricas, todo suntuoso». En cambio, Sánchez-Mesa Martín (1971: 95), afirma que «en conjunto, a pesar de haber intervenido dos manos distintas en la policromía, era tan corriente y extendida la manera tradicional [estofados con labor de grutescos] que difícilmente podremos distinguir la obra de Aragón y la de Raxis», si bien asigna las carnaciones en tonos mates y algo verdosos a Aragón y a Raxis las hechas a semipulimento, al igual que los fondos de los relieves.

30 Siendo muy conocidas la personalidad y producción de algunos de los posibles autores, como Juan Bautista Vázquez el Mozo o Pablo de Rojas, incorporamos aquí algunas noticias sobre los documentados. Así, Lázaro de Velasco, hijo del célebre Jacobo Florentino "El Indaco", fue clérigo, iluminador de libros cantorales y primer traductor al castellano 
personalidad de los escultores sigue en los terrenos del atribucionismo, aunque hay coincidencia absoluta en el valor del conjunto como punto de confluencia e interrelación entre el romanismo sevillano y el granadino.

\section{Historia constructiva}

Diferentes noticias documentales parecen arrojar alguna luz sobre el largo proceso de construcción de esta maquinaria. El alhajamiento de la capilla mayor se prolongó en el tiempo no sólo por las desavenencias con Diego de Siloé, dirimidas mediante los autos judiciales de 1548. Debe tenerse también en cuenta, como sugiere Bustamante García, las circunstancias personales del comitente, que tuvo muchas dificultades económicas, hasta tal punto que en sus últimos días hubo de ser mantenido por el propio rey en secreto. ${ }^{31}$

Las dificultades económicas motivarían que el duque de Sesa se viese obligado por escritura de 30 de agosto de 1568 a traspasar a los jerónimos el valioso cortijo de Ánzola, valorado en la importante suma de 29.000 ducados. Con esta transacción quedaba desligado de dos importantes cargas: la capellanía fundada por su abuela doña María Manrique en 1525 , con una renta anual de 50.000 maravedíes y 400 fanegas de trigo, por un lado; y, por otro, la obligación de ultimar el panteón familiar: «que el dicho convento de San Jerónimo ha de hacer y arreglar la dicha capilla del señor Gran Capitán a su costa..., conforme a la orden y traza que por mi fuere ordenado». ${ }^{32}$ De esta manera, los monjes pudieron realizar a su costa la escalinata del presbiterio, la solería de mármoles blancos y negros, la lauda sepulcral, ${ }^{33}$

del tratado de Vitrubio; como arquitecto, sólo se conocen su papel como tracista, junto con Martín de Baseta, de la iglesia de la Compañía de Jesús de Granada, la realización de informes para las catedrales de Jaén y Granada y sus intentos de maestría de obras para esta última y la fachada de la Real Chancillería. Véase Gómez-Moreno Calera 1989. Juan de Aragón, amigo del anterior, trabajó en los retablos de la parroquial granadina de San Cristóbal, convento de carmelitas calzadas, e iglesias de Colomera y Gabia; su mejor obra, un Cristo atado a la Columna, se conserva en el Museo de Bellas Artes de Granada: Gómez-Moreno Calera 2010: 253. Para Pedro de Raxis, gran policromador conocido como "E padre de la estofa", recomendamos la lectura del siguiente artículo: Gila Medina 2003. Sobre Diego de Navas ya hemos mencionado su intervención en el desparecido retablo de la Antigua de la Catedral de Granada, conservándose el retablillo de 1588 ubicado en el interior de la alhambreña Puerta de la Justicia. De Pedro de Orea cabe consignar, amén de la portada de la propia iglesia de San Jerónimo, las trazas y labra de la principal de la parroquia de San Pedro y San Pablo de Granada: Gallego Burín 1996: 66 y 350.

31 Bustamante García 1995: 14-18. Era el tercer duque de Sesa y nieto del Gran Capitán, don Gonzalo Fernández de Córdoba (15241578), gobernador de Milán entre 1554 y 1560.

32 Marín López 1999: 233. La citada renta de 50.000 maravedíes al año estaba impuesta de la siguiente manera: 30.000 maravedíes sobre la villa de Órgiva, en la Alpujarra y 20.000 sobre ciertas huertas en la ciudad de Granada (Abdemiraz, Aceytuno, Geninçial y Lugo). Las 400 fanegas de trigo se recogían en el mismo cortijo de Ansola, Anzola, Ansula o Anzula, según aparece citado, que estaba ubicado cerca de la localidad granadina de Pinos Puente.

33 Pieza de gran sencillez, en el centro del pavimento, que en términos humanistas aclara el significado de toda la capilla como memoria fúnebre y monumento del Gran Capitán: GONZALI FERNANDEZ DE CORDOVA QVI PROPIA VIRTVTE MAGNI DVCIS NOMEN PROPRIVM SIBI FECIT OSSA PERPETVAE TANDEN LVCI RESTITVENDA HVIC INTEREA LOCO púlpito, reja y retablo, si bien siempre bajo la atenta mirada de los duques. ${ }^{34}$

Con todo, el inicio del retablo tuvo que esperar varios años, hasta la finalización de la rebelión de los moriscos de Granada (1568-1570) y el acopio de rentas suficientes procedentes del citado cortijo de Ánzola, según se deduce del acta de 15 de septiembre de 1576, por la que se contrata la obra con Juan de Aragón. ${ }^{35}$ Tres años después, se aprueban las nuevas trazas de Lázaro de Velasco, más ricas y mayores, obligándose Aragón a ejecutarlas aún a costa de perder la mitad del aumento de trabajo que ello suponía.

Es posible que esta sustancial modificación tuviera mucho que ver con la idea de imitar en gran medida la disposición del gran retablo de la Capilla Real, realizado por Felipe Bigarny en la década de 1520, pero trascendiendo su estructura plana de cinco calles -como la franja central de la obra de San Jerónimo- con el añadido de otras en ángulo. Que el horizonte de la Capilla Real estuviera muy presente en el conjunto es una idea muy bien destacada por Bustamante García $^{36}$ a tenor de detalles como la escalinata de acceso al altar y las esculturas de los orantes en las esquinas, cuando tal disposición empezaba a ser retardataria. Pero, a pesar de este evidente sentido de emulación, no compartimos la opinión de Carrasco de Jaime, acerca de que las primeras trazas presentadas para el contrato con Juan de Aragón en 1576 habrían sido hechas decenios atrás por Jacobo Florentino, mientras que las de 1579 se encargarían a Lázaro de Velasco, por ser hijo de éste. ${ }^{37}$ Puestos a elucubrar, sería más lógico pensar en unas trazas propias de Siloé que circularan por el monasterio, habida cuenta del interés que este artífice mostró en realizar el retablo de su propia mano hasta su despido en 1548, y que ya no se ajustaran a los nuevos gustos de la época.

La obra estaba en pleno proceso en 1585, pero poco después experimentó un cambio de rumbo: ya se ha aludido a la reforma de 1603, según trazas de Pedro de Orea, pero

CREDITA SVNT. GLORIA MINIME CONSEPVLTA [Los huesos de Gonzalo Fernández de Córdoba, que con su valor se ganó el sobrenombre de Gran Capitán, están confiados a esta sepultura hasta la restitución de la luz eterna. Su gloria en modo alguno queda sepultada con él].

34 Moreno Olmedo 1988. Según el documento de venta del cortijo los monjes se obligaban a gastar cada año 800 ducados en la culminación de la capilla y su alhajamiento, debiendo presentar cuentas al duque de Sesa al final de cada trienio.

35 Rodríguez Molina 2009. Se transcribe parte del acta en la página 83, donde expone el prior lo siguiente: «si bien sería atento a que ha siete $u$ ocho años que poseemos el cortijo de Ansola que dio el duque de Sesa a esta casa, con obligación de que cada un año gastásemos 800 ducados en la obra de la reja y retablo y otras cosas, y en todo este tiempo no se ha gastado cosa alguna por haber rentado el cortijo poco y por haber estado la dicha casa muy alcanzada por las muchas pérdidas de hacienda que hubo en el tiempo de la guerra, y que pues ya la casa iba tornando en sí, que se hiciese el retablo conforme a cierta traza y condiciones que mostró al convento... y se diese a Juan de Aragón, pintor, vecino de esta ciudad de Granada».

36 Bustamante García 1995: 15.

37 Carrasco de Jaime 2007: 394. Su tesis se basa en la transcripción del Libro de Actas Capitulares del monasterio (Archivo Histórico Nacional, libro 3693, fol. 56), por la que, en acta de 15 de abril de 1579 «nuestro muy reverendo padre fray Diego de Santa María propuso al convento que por cuanto había sido informado de oficiales muy primos en el arte de la arquitectura que la traza del retablo no estaba bien hecha... que sería más acertado hacerse otra traza de nuevo, al cual hijo el licenciado Velasco». Gómez-Moreno Calera (2010: 249), por su parte, transcribe bien el final de esta cita: «la cual hizo el licenciado Velasco». 
dado que éste artífice había fallecido en 1592, lógicamente la decisión debió tomarse con anterioridad. La razón por la que dichas trazas no se llevaron a efecto sino a principios del Seiscientos se debe al pleito que mantuvo la comunidad religiosa con Juan de Aragón (no sabemos si el origen del litigio estaría en cuestiones de tasación o por el cambio de trazas) y, muerto éste poco después de 1594, con su viuda, María de Tudela, que se solventó en el año citado de 1603 con un pago de 1.100 ducados y una renta vitalicia para ella, hasta su muerte en $1616 .{ }^{38}$

Por tanto, serían cuestiones presupuestarias junto a disputas judiciales, los motivos por los que la obra se alargaría tantos años, llegándose a reinterpretar algunas partes tardíamente debido a los cánones imperantes a finales del siglo XVI. ${ }^{39} \mathrm{Y}$, desde luego, el recuerdo de lo onerosa que resultó la empresa perduraría en el recuerdo, a tenor del comentario que hizo el cronista Henríquez de Jorquera a mediados del siglo xvlı: «su mayor capilla es una de las mejores que se reconocen, crucero y cimborrio, y su retablo es de grandiosa y costosa escultura, que costó gran número de ducados». ${ }^{40}$

\section{Iconografía}

Otra vía de avance en nuestro conocimiento de esta gran maquinaria estriba en el análisis iconográfico. Desde este punto de vista, las contribuciones más interesantes se deben al profesor Martínez Medina, que se ha centrado fundamentalmente en su interpretación como programa cristológico-salvífico dedicado al misterio de la Redención, muy apto para un lugar concebido como panteón de la gloria póstuma. Este es el más completo ciclo de la vida de Jesucristo en el arte granadino, después del conjunto de vidrieras de la capilla mayor catedralicia. ${ }^{41} \mathrm{~A}$ este respecto, cabe mencionar de nuevo la coincidencia de planteamientos con los grandes programas imperiales de la ciudad, como son las citadas vidrieras que forman parte del espacio funerario diseñado por Siloé como regio sepulcro de los Austrias ${ }^{42}$ y, nuevamente, la reja y retablo de la Capilla Real, si bien centrados sólo en los temas de la Pasión.

El programa cristológico del retablo arranca en el primer cuerpo con la Infancia de Jesús, a través de la Adoración de los Pastores y la Epifanía. Se omite la Vida Pública en el segundo, que tiene carácter mariano, centrado en la Inmaculada Concepción (a esta advocación está dedicado el templo) y y con la compañía de la Anunciación y Presentación de Cristo -éste, más en función de la Purificación de la Virgen que de la figura de Jesús-. El tercero y cuarto se

38 Gómez-Moreno Calera (2010: 251) apunta el autor cómo, por la ampliación de 1603, Diego de Navas y Pedro de Raxis cobrarían, respectivamente, las cantidades de 8.250 y 8.750 reales.

39 Rodríguez Molina 2009: 22. En 1585 las rentas de Ansula o Ánzola debían dar lo justo para el retablo, dado que se discutió la conveniencia de poner «una reja de madera en la capilla mayor, pues la otra que había no se podría poner por su antigüedad y vejez y estaba hecha pedazos», acordándose lo dicho, "pues la de hierro no se puede poner ni hacer tan presto». Habría que esperar hasta 1601 para la culminación de la reja definitiva.

40 Henríquez de Jorquera 1987.

41 Martínez Medina 1989: 25-27.

42 Véase: Nieto Alcaide 2002. dedican a la Pasión: uno con los relieves de la Oración en el Huerto, Prendimiento, Jesús orando antes de la Crucifixión y Descendimiento, acompañado de las esculturas de Jesús a la Columna y el Ecce Homo; y, el otro, con la Ascensión de Cristo, Pentecostés y el grupo del Calvario bajo el Padre Eterno, que da fe de la verdad de todo lo representado.

En torno a estos temas se articulan los demás personajes, si bien para Martínez Medina «el orden del programa y su correspondiente ubicación no guarda ya la sistemática que observamos en los otros grandes conjuntos de la primera mitad del mismo siglo». Cabe mencionar desde este punto de vista la gesta histórica, representada en las figuras orantes de don Gonzalo Fernández de Córdoba y doña María Manrique, con sus escudos de armas, o la dimensión simbólica efigiada en las Virtudes Teologales (Fe, Esperanza y Caridad) y Cardinales (Prudencia, Fortaleza, Justicia, Templanza) del ático, o los fundamentos de la Doctrina reflejados en el banco: los evangelistas Juan, Marcos, Mateo y Lucas, junto a parejas de Santos Padres formadas por Jerónimo y Agustín, más Ambrosio y León ${ }^{43}$-éste en lugar del habitual Gregorio Magno-, que alternan con dos grandes oradores: Bartolomé e lldefonso.

Por nuestra parte, añadimos algunas reflexiones, sin ahondar por completo en la complejidad de un programa que parece encauzarse hacia las nuevas líneas del pensamiento contrarreformista. Quizás sea en el sotabanco, añadido a principios del siglo XVIl, donde se advierte mayor diversidad: en sus extremos se constata la misma alternancia que en general en las calles angulares del retablo, entre santos y santas, como contrapunto o reflejo de los capitanes cristianos a quienes se dedica el panteón: las parejas de Esteban y Lorenzo, Cosme y Damián, Úrsula y Susana, más María Egipciaca como programa hagiográfico donde caben lo sanador, lo martirial, la penitencia o la obediencia, amén de los santos caballeros Constantino y San Martín en lugar privilegiado, flanqueando el altar, como trasunto de la virtud heroica del comitente.

El primer cuerpo, centrado por el manifestador, presenta a sus lados los dos grandes pilares de la iglesia, Pedro y Pablo, los relieves de las santas principescas Margarita y Catalina con Bárbara y los bultos de dos fundadores monásticos, como son Bernardo y Benito. En el segundo cuerpo, amén de los temas mariológicos citados más arriba, aparecen los dos Santos Juanes en las entrecalles principales, en clara emulación a los titulares del retablo de la Capilla Real como santos patronos de los Reyes Católicos; asimismo, santas ejemplares de penitencia y oración, como son María Magdalena y la pareja de jerónimas Paula y Eustoquia, amén de los bultos de los dos grandes fundadores mendicantes: Domingo de Guzmán y Francisco de Asís. El tercero está casi íntegramente dedicado a la Pasión de Cristo, con la compañía del relieve central con San Jerónimo penitente, como fundador de la orden, y de dos apóstoles en bulto redondo: Santiago y Andrés. Y, en el ático, junto a los temas citados más arriba estarían los santos Justo y Pastor, a cuya parroquia pertenece el monasterio. ${ }^{44}$

43 Martínez Medina 1989: 226-229.

44 La que debiera ser imagen de San Pastor es en realidad un "intruso": perdido en otro tiempo, fue sustituido a principios del siglo xx por una escultura más moderna que parece corresponder a un santo apóstol. Tampoco es la original la virtud de la Prudencia, ubicada en el 
Las imprecisiones del programa iconográfico, por otro lado, pueden justificarse por la larga historia constructiva del retablo y por las modificaciones realizadas a lo largo de su ejecución. Así, es posible que ni la Adoración de los Pastores, en el primer cuerpo, ni la Presentación en el Templo, formaran parte del programa inicial, y de ahí que sean de una mano y material diferentes que los de la Epifanía y Anunciación que les acompañan. ${ }^{45}$

\section{Fuentes visuales}

El cotejo de fuentes iconográficas para conocer los procesos de creación y de difusión de la obra de arte es una metodología que ha dado buenos frutos entre la historiografía reciente, especialmente en lo que se refiere a la producción pictórica, ${ }^{46}$ aunque también ha suscitado interés entre los estudiosos dedicados al ámbito de lo escultórico. ${ }^{47}$ En el caso que nos ocupa sus resultados pueden tener una gran importancia, dados la peculiaridad del retablo de San Jerónimo como crisol de influencias entre artistas de diversa procedencia y formación y su valor transicional entre el romanismo y los inicios de la escultura barroca andaluza en sus dos grandes centros, Sevilla y Granada.

Las esculturas y relieves del retablo de San Jerónimo destilan en general una serena elegancia enmarcada en la difusión de los ideales manieristas. Así, las efigies de Jesús a la Columna y Ecce Homo, comparten un mismo espíritu olímpico y esteticista con los grabados del mismo tema de Cornelis Cort.

Por su parte, el San Juan Evangelista en la tina viene a ser una versión purista del mismo tema hecho por Bigarny en la Capilla Real, con un tratamiento anatómico mucho más cuidado y mayor concentración espiritual, al suprimirse los sayones aprestados a martirizar al santo; al tiempo, la propia tina presenta un perfil marcadamente clásico, recordando, como sugiere García Luque a propósito del relieve de San Juan ante Porta Latina tallado por Juan Martínez Montañés hacia 1638 (hoy en el Museo de Bellas Artes de Sevilla), una relación muy estrecha con una estampa de Marcantonio Raimondi dedicada al martirio de Santa Cecilia, abierta sobre composición de Rafael. ${ }^{48}$

extremo a la izquierda del cuarto cuerpo, pues en realidad se trata de un San Juan Evangelista (quizás por ello Gómez-Moreno González la consignó como de mano diferente a las demás Virtudes), y, en fin, también es un añadido la pequeña Inmaculada que centra el manifestador. Debo estas indicaciones a la generosidad del profesor Gómez-Moreno Calera.

45 A este respecto, cabe citar la noticia aportada por: Martínez Justicia 1996: 49, acerca de cómo «en 1691, en tiempos del prior de esta casa, fray Bartolomé de San Agustín, se reparó que las imágenes de Nuestra Señora y de nuestro padre San Jerónimo estaban mal colocadas, porque siendo Nuestra Señora la titular debía estar mediata después del arca del Santísimo, y nuestro padre San Jerónimo en el nicho más arriba». El cambio a la posición actual se realizó en 1693, lo que invalida en cierto modo la lectura iconográfica citada más arriba del segundo cuerpo del retablo como discurso puramente mariológico.

46 Véanse, por ejemplo: Navarrete Prieto 1998; Navarrete Prieto, Zapata Fernández de la Hoz y Martínez Ripoll 2008.

47 Se trata, sobre todo, de artículos de revistas. He aquí una pequeña muestra al respecto: Belda Navarro 1986; González García 1991; Oricheta García 1996; García Álvares 1997; Andrés González 1999.

48 García Luque 2013. Las proporciones de la tina, con adornos de veracidad arqueológica, y la disposición del mártir como orante, están
La relación con fuentes grabadas previas y con versiones posteriores del mismo tema también aparece en la efigie vecina de San Juan Bautista sosteniendo el libro con el Cordero Místico. El modelo de inspiración podría estar en una estampa del mismo tema de Cherubino Alberti, sobre composición de Federico Zuccaro, que ha sido relacionada con dos esculturas del mismo santo: una realizada por Martínez Montañés hacia 1623 para uno de los retablos laterales del convento sevillano de Santa Clara; la otra, tallada en fecha similar por Juan de Mesa para la Cartuja de las Cuevas de Sevilla y que hoy se guarda en el Museo de Bellas Artes hispalense (Fig. 7).

\section{FIGURA 7}

San Juan Bautista. Cherubino Alberti y Juan Bautista Vázquez el Mozo (atrib.). Foto: José Carlos Madero López
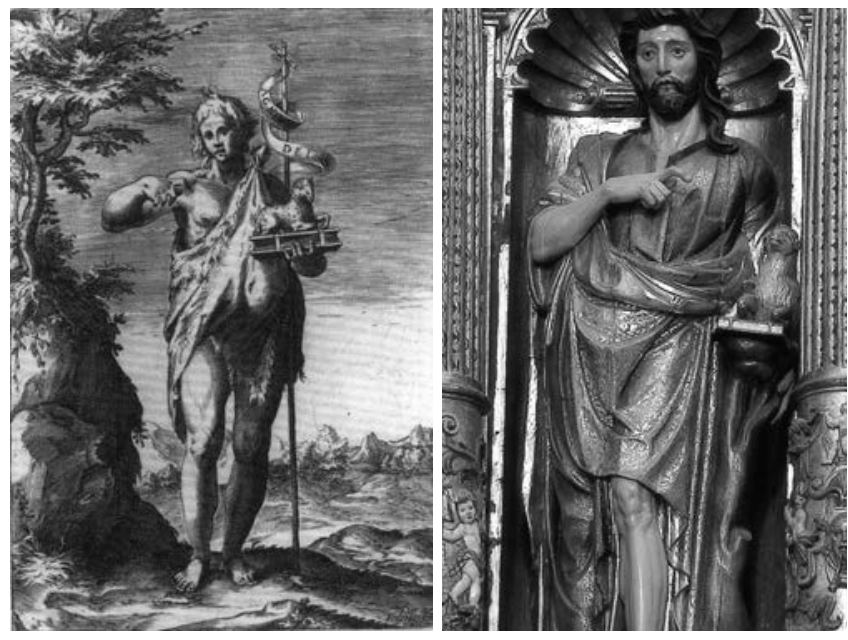

En ambos casos está presente el acusado contraposto, la forma de señalar con el dedo flexionado al cordero y la disposición del manto del Precursor en una acusada diagonal, aunque en el grabado la propensión al desnudo es bastante mayor. Pues bien, la disposición de ambas figuras ya está claramente presente en la imagen homónima del retablo de San Jerónimo, aunque con la particularidad de estar representado el santo con barba, frente al modelo imberbe de las versiones citadas, y con el añadido de un sencillo tronco de árbol sobre el que apoya el libro. Podría pensarse, como sugiere García Luque, en el manejo de fuentes comunes en los talleres de escultura, sin descartar el conocimiento que del conjunto granadino tuviera Martínez Montañés en sus años de formación junto a Pablo de Rojas. ${ }^{49}$

Seguramente podría rastrearse el influjo italianizante a través de grabados en otras esculturas exentas, como las elegantes Virtudes, o en el grupo del Calvario, tan deudor, como muchos otros coetáneos en pintura o escultura, de las versiones grabadas por Wierix o los Sadeler. La búsqueda de relaciones se antoja más complicada con respecto a los

claramente inspiradas en el grabado de Raimondi, como puede verse en su reproducción en: Strauss (ed.) 1978: t. 26, vol. 14 (parte 1), 153-154. La relación de la obra montañesina con la escultura del retablo jeronimiano es nuestra.

49 García Luque 2013: 229-230. La alusión a la efigie del retablo granadino es del autor. La comparación entre el grabado y las esculturas sevillanas citadas procede de: Navarrete Prieto y Pérez Sánchez (coms.) 2005. 
diferentes santos que aparecen tanto en bulto redondo como en altorrelieve, por tratarse de composiciones presentativas que se mueven dentro de escasas variantes iconográficas.

Mayor interés tienen en este sentido las grandes escenas en relieve, más proclives a la imitación de las estampas, como bien afirma Arias Martínez:

La fortuna de su empleo [a propósito de la difusión de los grabados de Johan Sadeler I] se deja ver en la pintura, pero también en el relieve escultórico, que siempre buscó calidades pictóricas en su resultado final. Se aleja, sin embargo del uso de la fuente en el caso de la escultura de bulto redondo, mucho más susceptible de mostrar la capacidad plástica del artista, al tratarse de recreación de objetos tridimensionales y donde la estampa sólo podía servir para una caracterización parcial y mucho menos detectable. ${ }^{50}$

En varios relieves se evidencia la relación de dependencia iconográfica, pero también como fórmula de prestigio, con respecto a obras granadinas de edificios emblemáticos. Así, el hermoso relieve del encasamiento central del tercer cuerpo, dedicado a San Jerónimo Penitente, es un tema que ya se perfiló en 1565 como remate de la puerta catedralicia de San Jerónimo, atribuido a Diego de Pesquera, y que sigue muy directamente al que labrara Diego de Siloé para el retablo de la capilla del Condestable en la catedral de Burgos. ${ }^{51}$ Su presencia en la catedral se justifica no sólo por su cercanía a la calle del mismo nombre, que conduce hasta el monasterio, sino también por los dos prelados pertenecientes a la orden jerónima que tuvo la archidiócesis granadina en la primera mitad del Quinientos: fray Hernando de Talavera (14921507) y fray Pedro Ramiro de Alba (1526-1528).

\section{FIGURA 8}

San Jerónimo Penitente. Diego de Pesquera (catedral de Granada) y Juan Bautista Vázquez el Mozo (atrib.). Fotos: José Carlos Madero López
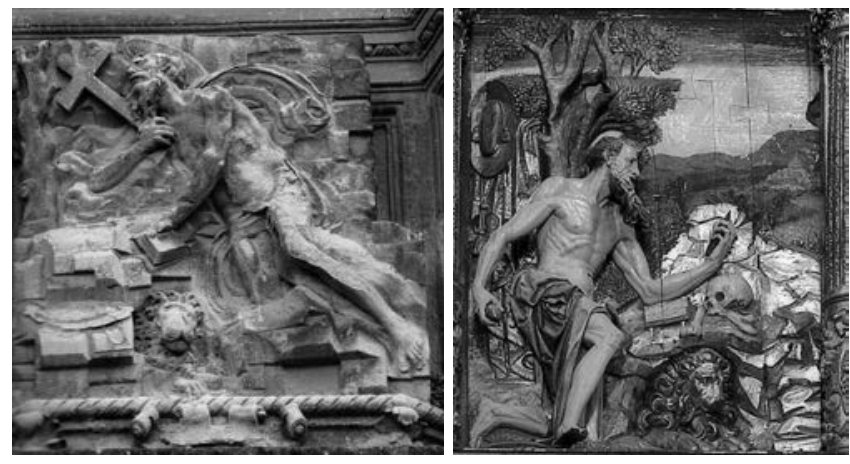

En realidad la figura jeronimiana del retablo es diferente a la tensa y helicoidal efigie de Pesquera, teniendo como referente muy cercano la célebre terracota de Pietro Torrigiano, hoy en el Museo de Bellas Artes de Sevilla, en la disposición de brazos, piernas y torso (otra lección que pudo aprender Martínez Montañés en Granada antes de formarse en Sevilla, en su obra para el monasterio de Santiponce); sin embargo, el fondo del relieve, mostrando al león de frente cobijado en la oquedad de una roca que sirve de base al santo para apoyar un libro, deriva directamente del modelo

\footnotetext{
50 Arias Martínez 2002.

51 Sánchez-Mesa Martín: 393.
}

de Siloé y Pesquera (Fig. 8): un curioso sincretismo en una obra de alta calidad, muy por encima del torpe relieve pétreo de la propia portada de la iglesia de San Jerónima, labrada hacia 1590 por Pedro de Orea y Martín Díaz Navarrete.

También puede vincularse a la catedral granadina, en cierto modo, la imagen titular de la iglesia, la Inmaculada con bustos de San Joaquín y Santa Ana a sus pies, que responde al tema de la leyenda de los tallos representado en una de las vidrieras de su girola, diseñadas según afirma Nieto Alcaide, por el propio Diego de Siloé y ejecutadas por Juan del Campo y Teodoro de Holanda. Se sigue la idea de vincular la efigie de la Virgen a sus progenitores como flor del árbol de Jessé, pero en la vidriera aparece la Virgen con el Niño, mientras que en el retablo aparece plenamente formada la iconografía inmaculista. ${ }^{52}$

\section{FIGURA 9}

Ascensión de Cristo. Teodoro de Holanda (catedral de Granada) y Pablo de Rojas o Martín de Aranda (atrib.). Fotos: José Carlos Madero López
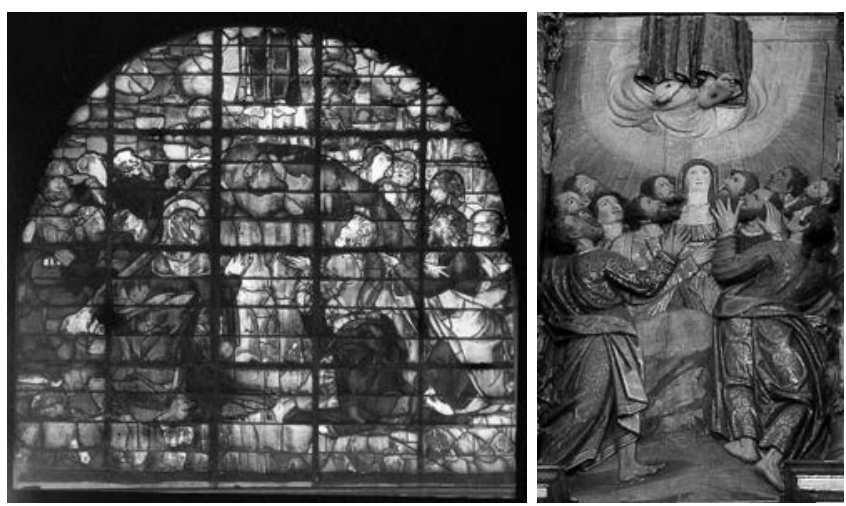

Mayor relación encontramos aún con respecto al relieve de la Ascensión de Jesús -en el ático- y la correspondiente vidriera de la girola catedralicia (Fig. 9). Se trata de una interpretación de tradición medieval, ya entonces en desuso, presentando sólo la parte inferior del cuerpo en ascenso de Cristo, con la Virgen y los discípulos congregados junto al monte Oliveto, en cuya cima quedan impresas las huellas del Salvador. ${ }^{53}$ La vidriera sigue de cerca el grabado de Durero del mismo tema, correspondiente a la Pequeña Pasión, mientras que en el relieve se introduce la novedad de colocar a María jerárquicamente en el centro de la escena, creemos que para mantener correspondencia figurativa con el otro relieve del ático -ambos relativos a las trazas que diera a principios del siglo XVII Pedro de Orea-, dedicado a Pentecostés, donde la figura de Cristo es sustituida en la composición por la Paloma del Espíritu Santo.

A las conexiones con los programas catedralicios hay que unir las evidentes relaciones con el gran retablo de la Capilla Real, apenas señaladas hasta hoy más allá de

52 Véase: Nieto Alcaide 1973. Hay que tener en cuenta que el programa de las vidrieras fue inspirado por el arzobispo de Granada, y monje jerónimo, fray Pedro Ramiro de Alba. La vidriera en cuestión fue realizada entre 1554 y 1556 por Teodoro de Holanda.

53 Ibídem: 297-298. En la propia iglesia de San Jerónimo se conservan restos de una vidriera realizada por Juan del Campo, del mismo tema y con una composición muy similar. Véase también: Nieto Alcaide 1975. Se realizaría entre 1544 y 1550. 
los paralelismos existentes en las figuras de los donantes arrodillados en las repisas de las esquinas y alguna otra notable excepción. Ya señaló en su día la profesora Martínez Justicia cómo «de la versión de la Capilla Real, aún con ciertos recuerdos gotizantes, deriva, en cuanto a composición se refiere, el bello relieve de la Piedad de la iglesia de San Jerónimo», ubicado en el tercer cuerpo del conjunto y atribuido a Vázquez el $\mathrm{Mozo}^{54}$ (Fig. 10). Los paralelismos en cuanto al grupo de la Virgen con Cristo en su regazo y San Juan son muy marcados, siendo diferente el resto de la composición, pues en la Capilla Real figuran una de las Santas Mujeres arrodillada y los Santos Varones de pie, mientras que en el tablero jeronimiano observamos una de las Marías de pie, con el rostro cubierto, y a María Magdalena, separadas ambas por el madero.

FIGURA 10

Piedad. Felipe Bigarny (Capilla Real de Granada) y Juan Bautista Vázquez el Mozo (atrib.). Fotos: José Carlos Madero López
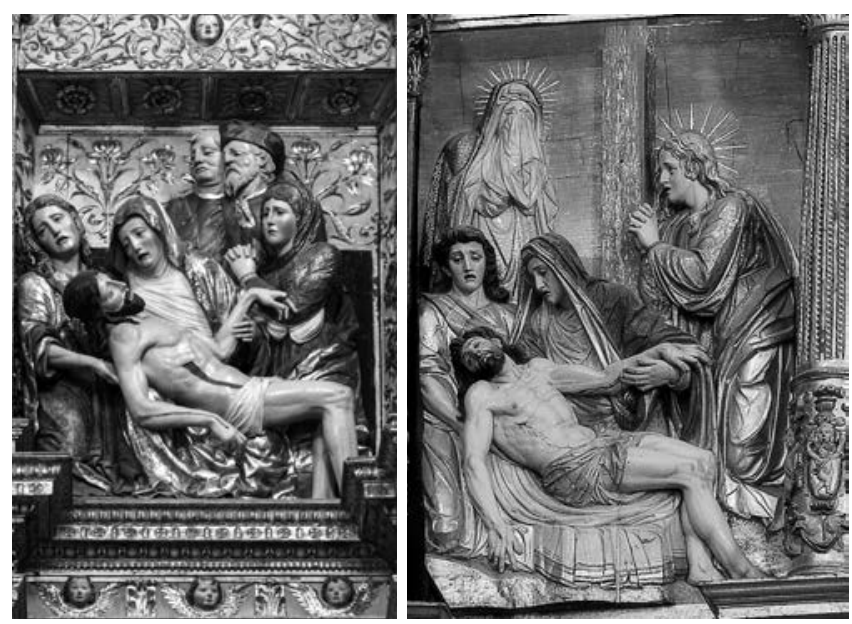

También al deseo de emulación de los tesoros de la Capilla Real, creemos, se puede vincular el relieve correspondiente a la Oración en el Huerto de los Olivos. La composición de Jesús orante, con el pequeño ángel confortador a su derecha volando en diagonal sobre el grupo de los tres apóstoles adormilados y apiñados en las rocas, parece seguir de cerca el tema homónimo en la reja del presbiterio, labrada por Bartolomé de Jaén (Fig. 11), así como la deliciosa tabla atribuida a Sandro Botticelli, que donara otrora la reina Isabel y hoy se expone en su Museo. Se trata, en todo caso, de una composición ligada a prototipos que circularon ampliamente desde finales del siglo XV, con pocas variaciones iconográficas, como muestra un grabado del mismo tema, realizado por Martin Schongauer. ${ }^{55}$

54 Martínez Justicia 1996: 239. En nuestra opinión, el tema de la Capilla Real, a pesar de su origen medieval nórdico, presenta una fuerte relación con un dibujo del mismo tema conservado en la Apelles Collection y atribuido a Alonso de Berruguete, que vendría a remarcar la influencia de este maestro sobre Felipe Bigarny en los inicios de la década de 1520, cuando ambos formaron mancomunidad de trabajo. Véase: Cruz Cabrera 2014: 198.

55 Ibídem: 216. El grabado mencionado puede verse en: Strauss (ed.) 1978: vol. 8, part. 6, 222. En cambio, no se aprecian influjos del relieve de la Oración en el Huerto que forma parte del mausoleo labrado
FIGURA 11

Oración en el Huerto. Bartolomé de Jaén (Capilla Real de Granada) y Juan Bautista Vázquez el Mozo (atrib.). Fotos: José Carlos Madero López
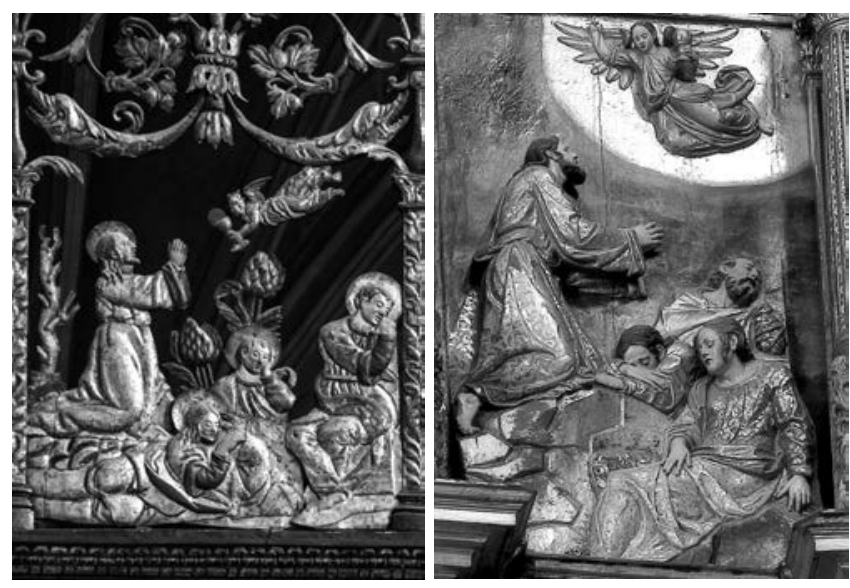

No hemos hallado correspondencias figurativas respecto a los relieves de Jesús meditando antes de la Crucifixión y de la Presentación en el Templo, en el tercer y segundo cuerpo respectivamente. De todas formas cabe decir que el primero, atribuido a Vázquez el Mozo y punto de arranque de una iconografía de gran éxito en la Granada barroca, como será el tema de Jesús de Humildad y Paciencia, es un tema de sensibilidad nórdica cercano a versiones grabadas por Durero; el segundo, más tardío, es bastante torpe en su ejecución, y pudiera estar inspirado en un sencillo grabado xilográfico.

Mucho más patentes son las sugestiones de la estampa en el caso de los restantes relieves de este magno ciclo dedicado a la figura de Cristo. Así, el influjo de Alberto Durero es muy fuerte en el Prendimiento, del tercer cuerpo del retablo; no obstante hay que hacer notar que no se trata tanto del parecido con la estampa de la Pequeña Pasión cuanto con las versiones que de ella hicieron otros artistas posteriormente, en especial Pieter Huys (Fig. 12) o Giulio Clovio, de las que están captados detalles tan específicos como los cascos de los captores o la antorcha que ilumina la escena, sin faltar los dos episodios dramáticos simultaneados del beso de Judas y del ataque de Pedro al soldado Malco. ${ }^{56}$

Otro tanto ocurre con la Adoración de los Reyes Magos -primer cuerpo del retablo-, donde la disposición escalonada de los personajes sobre un fondo arquitectónico, el ordenamiento general de la escena y la actitud dialogante de los reyes presentan de nuevo claras relaciones con una estampa de Alberto Durero de hacia 1506, así como con versiones posteriores inspiradas directamente en ella, como la de Giulio Clovio sobre composición de Cornelis Cort (Fig.13), la de Pietro Palombo ${ }^{57}$ o la de Bernardino Passeri. ${ }^{58}$ Ello evidencia la enorme difusión que tuvo a lo largo del Quinientos aquella creación del artífice alemán, y que en

por Bartolomé Ordóñez para los reyes doña Juana y don Felipe. Debe tenerse en cuenta que este sepulcro permaneció oculto hasta su montaje en 1603.

56 Reproducción de estas obras puede encontrarse en: Strauss (ed.) 1978: vol. 18, 35

57 Reproducida por: González de Zárate 1992: 120.

58 Puede verse reproducida en: Strauss (ed.). 1978: vol. 34, 47. 
FIGURA 12

Prendimiento de Cristo. Pieter Huys y Juan Bautista Vázquez el Mozo (atrib.). Foto: José Carlos Madero López
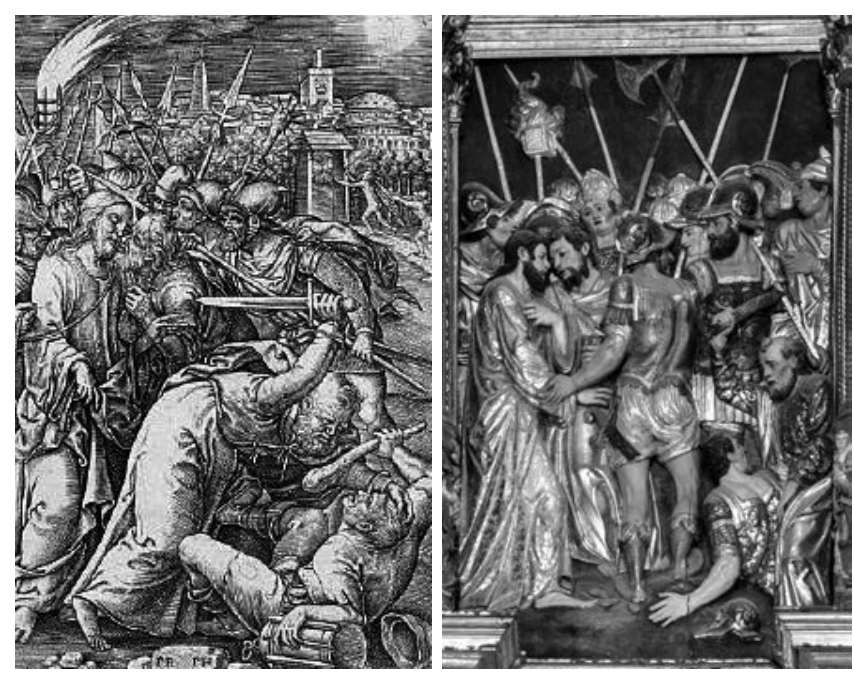

FIGURA 13

Epifanía. Cornelis Cort y Juan Bautista Vázquez el Mozo (atrib.). Foto: José Carlos Madero López
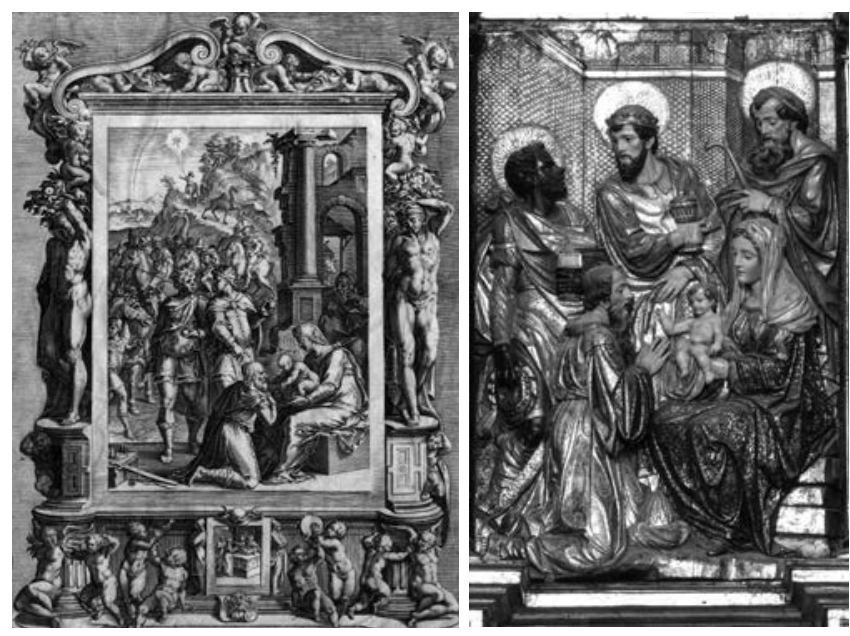

cierto modo está presente también en la vidriera que para este monasterio granadino hizo hacia 1550 Arnao de Vergara, y que hoy se encuentra en el Museo de Santa Cruz de Toledo. ${ }^{59}$

Otro relieve atribuido, como los dos anteriores, a la mano de Juan Bautista Vázquez el Mozo, parece en cambio haberse inspirado directamente en el arte italiano, que tan buenas versiones había dejado del tema de la Anunciación a lo largo del siglo XVI. En este caso se observa una cierta integración o fusión de modelos: la Virgen del tablero de

59 La citada vidriera se encuentra hoy guardada en el almacén del Museo. Perteneciente a la fachada principal de la iglesia de San Jerónimo, fue depositada por la Universidad de Granada en el entonces Museo Nacional de Santa Cruz de Toledo en la década de 1950, a instancias del Director General de Bellas Artes, el granadino Antonio Gallego y Burín. Las monjas jerónimas que hoy habitan el monasterio han intentado en reiteradas ocasiones su recuperación; infructuosamente, dado que el levantamiento del depósito recae en la institución universitaria, y no en ellas, al tener el edificio monacal no en propiedad, sino cedido por 100 años, a contar desde 1973.
San Jerónimo sigue muy de cerca el conocido grabado de Cornelis Cort, de hacia 1580, que reproduce el fresco de Zuccaro para la Annunziata de Florencia, pero su rostro se coloca en disposición casi frontal, para adaptarse mejor a las condiciones de visión del relieve ${ }^{60}$ (Fig. 14); por otro lado, la escenografía, con la presencia de la Paloma del Espíritu Santo y el Padre Eterno, así como la figura del ángel, son muy similares a lo efigiado en el grabado de Bernardino Passeri del mismo tema que ilustra el libro de Lorenzo Gambara, Rerum Sacrarum, de 1577 (Fig. 15). ${ }^{61}$ La cercanía de las fechas de las estampas con respecto al relieve, de todas formas, puede sugerir más coincidencia de modelos que influjos directos, si bien está fuera de toda duda la modernidad estilística del autor de estas obras.

\section{FIGURA 14}

Anunciación. Juan Bautista Vázquez el Mozo (atrib.), con detalle del grabado homónimo de Cornelis Cort sobre composición de Zuccaro. Foto: José Carlos Madero López

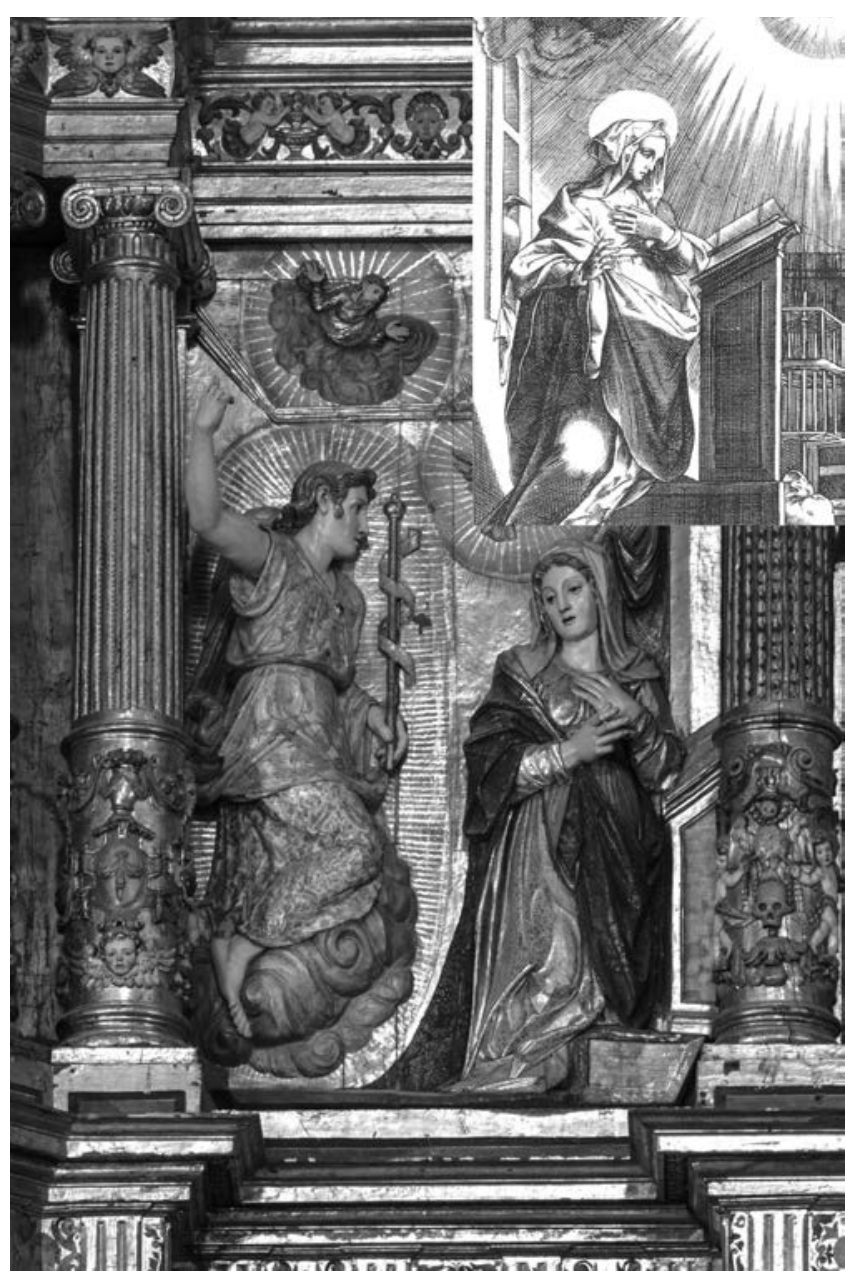

Finalmente, el relieve atribuido unánimemente a Pablo de Rojas por la historiografía, la Natividad o Adoración de los Pastores, presenta un especial interés desde el punto de vista de las posibles fuentes de inspiración. En esta obra creemos que aflora la capacidad del artífice de integrar

60 Este grabado puede verse, por ejemplo, en: Navarrete Prieto 1998: 144.

61 Véase esta ilustración en: Strauss (ed.) 1978: vol. 34, 43. 


\section{FIGURA 15}

Anunciación. Bernardino Passeri y Juan Bautista Vázquez el Mozo (atrib.). Fotos: José Carlos Madero López
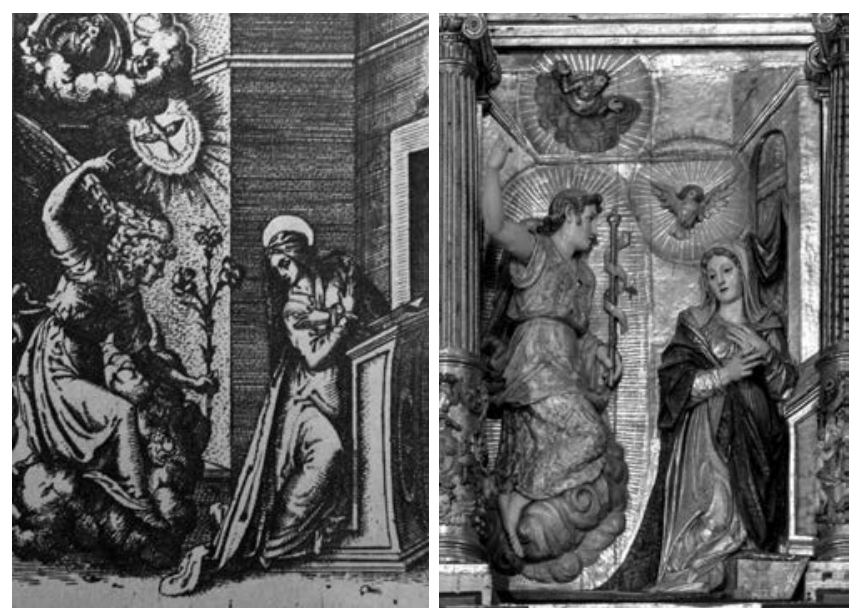

diversos modelos, como está acreditado en otras obras suyas. ${ }^{62}$ La parquedad de la escena en cuanto a personajes -la Virgen y San José flanqueando al Niño Jesús, con un ángel y un pastor en segundo término- no es habitual en los grabados quinientistas, que suelen ser prolijos en detalles y figuras, si bien encontramos un precedente muy directo en el tablero del mismo tema del coro catedralicio de Jaén, magno conjunto realizado hacia 1520 por dos tardogóticos, el flamenco Gutierre Gyerero y el vasco Juan López de Velasco, ${ }^{63}$ pero bajo la posible sugestión de Jacobo Florentino, quien terminó casado con una hija del segundo y de cuya descendencia nacería Lázaro de Velasco, precisamente uno de los tracistas del retablo granadino.

Esta posible línea de influjo, relacionable con la plausible presencia de unas exiguas trazas muy anteriores al tiempo de ejecución del retablo, puede apreciarse en la disposición general del tablero y en detalles singulares como el del pastor con una oveja sobre el hombro (Fig. 16); el cual, por otra parte, nos parece que tiene cierta relación compositiva con el dibujo de Miguel Ángel de un adolescente portando un ánfora, de 1505, que se conserva en el Louvre. ${ }^{64} \mathrm{EI}$ crióforo no es un detalle excesivamente abundante, y ello pensando en sus posibles implicaciones iconográficas alusivas al tema del Buen Pastor, pero podemos encontrarlo en estampas más o menos coetáneas a la época de ejecución del retablo. ${ }^{65}$

62 Véase: Cruz Cabrera 2014: 216-217. Dos ejemplos de la capacidad de Rojas de transformar modelos, son su San Sebastián de la parroquia homónima de Antequera, inspirado en la estampa de Bacanal de Dionisos con un tino, debida a A. Mantegna (Romero Torres 2004: 168), y su Cristo de la Paciencia de la iglesia de San Matías de Granada, que sigue la composición del Resucitado de Santa María sopra Minerva, de Miguel Ángel.

63 Sobre dicho conjunto véase: Domínguez Cubero 2012.

64 Preiis 1982

65 Así, por ejemplo, la Adoración grabada por Giorgio Ghisi (Strauss (ed.) 1978: vol. 31, 29).
FIGURA 16

Natividad. Juan López de Velasco (catedral de Jaén) y Pablo de Rojas (atrib.). Fotos: María Soledad Lázaro Damas y José Carlos Madero López
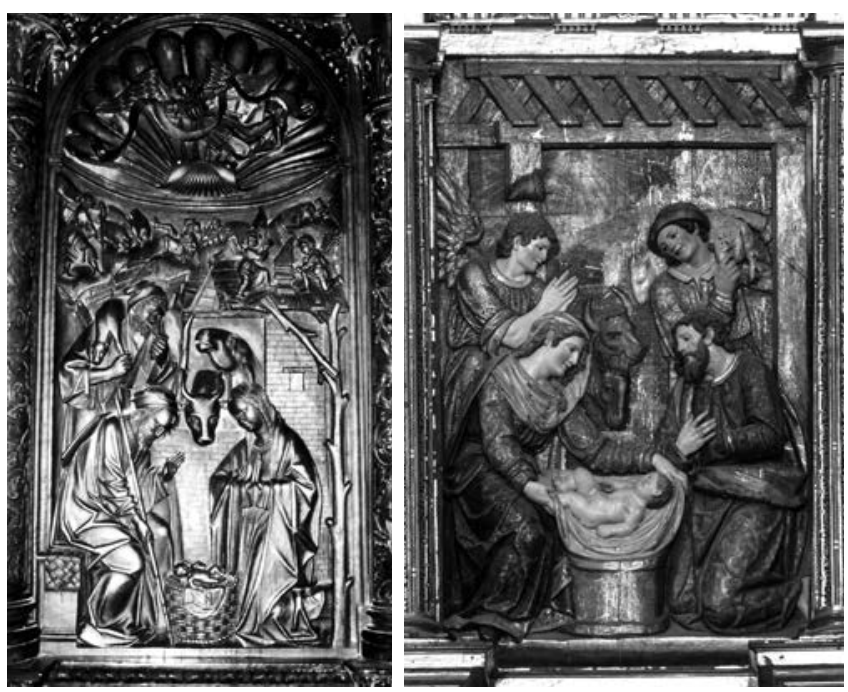

En definitiva, la complejidad de este magno conjunto de la retablística renaciente no sólo deriva de su larga historia constructiva y de la participación de varios artífices en la encrucijada de la formación de los centros escultóricos granadino y sevillano en el paso del idealismo romanista al naturalismo barroco También se debe al uso de diferentes repertorios visuales como fuente de inspiración, tales como la emulación de obras ligadas a los talleres imperiales de la ciudad y el uso de estampas: unas, como las derivadas de Durero, de gran difusión por su efectividad devocional; otras, de depurado sabor clasicista entre los grabadores italianos.

\section{BiBLIOGRAFÍA}

Andrés González, P. 1999. «Gregorio Fernández, Imberto y Wierix en el retablo mayor de las Isabelas de Valladolid». Boletín del Seminario de Estudios de Arte y Arqueología 65: 263-282.

Anguita Cantero, R.; Cruz Cabrera, J. P. y Gómez-Moreno Calera, J. M. 2006. Granada. Centro histórico (II). Granada: Ideal.

Arias Martínez, M. 2002. «La fortuna de los grabados de Sadeler en el ámbito leonés. Algunos ejemplos de su seguimiento en escultura y pintura entre los siglos XVI y XVII». De Arte 1: 89-106.

Azcárate Ristori, J. M. 1958. Escultura del siglo XVI. Ars Hispaniae, XIII. Madrid: Plus Ultra.

Belda Navarro, C. 1986. «Fuentes iconográficas y de inspiración en la escultura de Francisco Salzillo». Imafronte 2: 101-131.

Bermúdez de Pedraza, F. 1608. Antigüedad y excelencias de Granada. Madrid: Luis Sánchez.

Bernales Ballesteros, J. 1994. El arte del Renacimiento. Escultura, pintura y artes decorativas, Historia del Arte en Andalucía, vol. V. Sevilla: Gever

Bustamante García, A. 1995. «El sepulcro del Gran Capitán». Boletín del Museo e Instituto Camón Aznar 62: 5-41.

Bustamante García, A. y Marías Franco, F. 1982. «La catedral de Granada y la introducción de la cúpula en la España del Renacimiento». Boletín del Museo e Instituto Camón Aznar 8: 103-115.

Caballero Escamilla, S. 2014. «De la Edad Media a la Edad Moderna. Los Reyes Católicos, el arte y Granada», en J. P. Cruz Cabrera (coord.). Arte y cultura en la Granada renacentista y barroca: la construcción de una imagen clasicista: 225-258. Granada: Universidad. 
Callejón Peláez, A. L. 2008. Primus inter heroes: damas y guerreros en la decoración del monasterio de San Jerónimo. Granada: Mouliaá Map.

Carrasco de Jaime, D. J. 2007. «Documentos para una nueva aproximación al proyecto de la capilla mayor de San Jerónimo extramuros de Granada». Cuadernos de Arte e Iconografía 32: 385-422.

Ceán Bermúdez, J.A. 1800. Diccionario histórico de los más ilustres profesores de las Bellas Artes en España. Madrid: Viuda de Ibarra.

Colina Munguía, S. 1986. Monasterio de San Jerónimo de Granada. León: Everest.

Cruz Cabrera, J. P. 1999. «El mecenazgo religioso como imagen del poder. La fundación de la capilla mayor del convento de San Francisco de Baeza», en A. L Cortés Peña y M. L. López-Guadalupe Muñoz (eds.). Estudios sobre iglesia y sociedad en Andalucía en la Edad Moderna: 409-424. Granada: Universidad.

Cruz Cabrera, J. P. 2010. "La escultura quinientista granadina: de sus albores a Pablo de Rojas», en L. Gila Medina (coord.). La escultura del primer naturalismo en Andalucía e Hispanoamérica (1580 1625): 95-114. Madrid: Arco Libros.

Cruz Cabrera, J. P. 2014. «Fuentes visuales en la configuración de la escultura quinientista granadina», en J. P. Cruz Cabrera (coord.). Arte y cultura en la Granada renacentista y barroca. La construcción de una imagen clasicista: 185-224. Granada: Universidad.

Domínguez Cubero, J. 2012. El coro de la catedral de Jaén. Jaén: Fundación Caja Rural.

Espinar Moreno, M. y García Ruiz, A. L. 2003. Conocer y visitar el Monasterio de San Jerónimo. Granada: Natívola.

Gallego Burín, J. 1937. «Pablo de Rojas, el maestro de Martínez Montañés», en Homenaje a Martínez Montañés. Sevilla: Academia de BB. AA. Santa Isabel de Hungría.

Gallego Burín, A. 1996. Granada. Guía artística e histórica de la ciudad. Granada: Editorial Comares (ampliación de la edición original de 1946).

García Álvarez, C. 1997. "La transformación formal e iconográfica de modelos en cuatro ejemplos del arte renacentista en León». Estudios Humanísticos, Geografía, Historia, Arte 19: 273-288.

García Luque, M. 2013. «Fuentes grabadas y modelos europeos en la escultura andaluza», en L. Gila Medina (coord.). La consolidación del Barroco en la escultura andaluza e hispanoamericana: 179259. Granada: Universidad.

Gila Medina, L. 2003. «Aproximación a la vida y obra del pintor y estofador alcalaíno-granadino Pedro Raxis», Archivo Español de Arte 304: 389-406.

Gómez-Moreno Calera, J. M. 1989. «El licenciado Lázaro de Velasco, pintor de libros y arquitecto. Aproximación a su biografía y obra», Boletín de Arte 10: 75-92.

Gómez-Moreno Calera, J. M. 2010. «Evolución de la retablística granadina entre los siglos XVI y xvii», en L. Gila Medina (coord.). La escultura del primer naturalismo en Andalucía e Hispanoamérica (1580-1625): 239-272. Madrid: Arco Libros.

Gómez-Moreno González, M. 1892. Guía de Granada. Granada: Imp. de Indalecio Ventura.

Gómez-Moreno Martínez, M. 1931. La escultura del Renacimiento en España. Barcelona: Gustavo Gili.

Gómez-Moreno Martínez, M. 1983. Las águilas del Renacimiento español. Madrid: Xarait.

Gómez-Moreno Rodríguez, M. - E. 1951. Breve historia de la escultura española. Madrid: Dossat.

González de Zárate, J. 1992. Real colección de estampas de El Escorial. Vitoria: Ephialte.

González García, M. A. 1991. «El grabado en los libros litúrgicos de uso en España en los siglos XVI-XVII y su influencia en la pintura y la escultura». Revista virtual de la Fundación Universitaria Española, Tomo IV, 7.

Gutiérrez García, A. M.a 2007. El Monasterio de San Jerónimo de Granada. Musealización y puesta en valor de un monumento. Granada: Universidad, Proyecto Fin de Máster de Museología. Disponible en http://hdl.handle.net/10481/531.

Henríquez de Jorquera, F. 1987. Anales de Granada (1588-1646). Edición del manuscrito original por A. Marín Ocete. Granada: Universidad.

Hernández Díaz, J. 1982. "La escultura andaluza del siglo XVII», en La escultura y la arquitectura españolas del siglo XVII, Summa Artis, vol. XXVI: 38-39. Madrid: Espasa-Calpe.
López-Guadalupe Muñoz, J. J. 2010. «Pablo de Rojas, encrucijada de las escuelas andaluzas», en L. Gila Medina (coord.). La escultura del primer naturalismo en Andalucía e Hispanoamérica (15801625): 139-174. Madrid: Arco Libros.

Marías Franco, F. 1989. El largo siglo XVI. Los usos artísticos del Renacimiento español. Madrid: Taurus.

Marín López, R. 1999. «Origen y evolución del patrimonio del monasterio de San Jerónimo de Granada (siglos XVI-XVII)». Chronica Nova 26: 215-242.

Martín González, J. J. 1983. Escultura barroca en España, 1600-1770. Madrid: Cátedra.

Martínez, C. y Curiel, A. 2011. El Real Monasterio de San Jerónimo. Granada: llíberis.

Martínez Justicia, M. a J. 1996. La vida de la Virgen en la escultura granadina. Madrid: Fundación Universitaria Española.

Martínez Medina, F. J. 1989. Cultura religiosa en la Granada renacentista y barroca. Granada: Universidad.

Morales Martínez, A. J. 1992. "La otra arquitectura», en Arquitectura del Renacimiento en Andalucía. Andrés de Vandelvira y su época: 181-212. Jaén: Junta de Andalucía-Ayuntamiento de Jaén.

Moreno Olmedo, M.a A. 1988. «Monasterio de Nuestra Señora de la Concepción de la orden jerónima de Granada: sus privilegios». Cuadernos de la Alhambra 24: 143-149.

Navarrete Prieto, B. 1998. La pintura andaluza del siglo XVII y sus fuentes grabadas. Madrid: Fundación de Apoyo a la Historia del Arte Hispánico.

Navarrete Prieto, B. y Pérez Sánchez, A. E. (coms.) 2005. De Herrera a Velázquez: el primer naturalismo en Sevilla (catálogo de exposición): 26-27. Sevilla: Fundación Focus-Abengoa.

Navarrete Prieto, B.; Zapata Fernández de la Hoz, T. y Martínez Ripoll, A. 2008. Fuentes y modelos de la pintura barroca madrileña. Madrid: Arco Libros.

Nieto Alcaide, V. 1973. Las vidrieras de la catedral de Granada. Granada: Universidad.

Nieto Alcaide, V. 1975. «Juan del Campo: las vidrieras de San Jerónimo de Granada». Boletín Auriense: 281-286.

Nieto Alcaide, V. 2002. La vidriera del Renacimiento en Granada. Granada: Diputación Provincial.

Oricheta García, A. 1996. "Grabados alemanes y flamencos: Ios modelos de Juan de Juni y su escuela en León». Boletín de la Real Academia de Bellas Artes de San Fernando 83: 315-357.

Orozco Díaz, E. 1972. "La estética de Martínez Montañés y su formación granadina», en Martínez Montañés y la escultura de su tiempo: 108-133. Madrid: Dirección General de Bellas Artes.

Preiis, P. 1982. Miguel Ángel: Dibujos. Barcelona: Polígrafa.

Rodríguez Molina, J. 2009. «El monasterio de San Jerónimo de Granada. Patrimonio y más allá», Gazeta de Antropología 25. Disponible en http://www.ugr.es/ pwlac/G25_15Jose_Rodriguez_Molina.html

Romero Martínez, A. 1999. «Documentos para la historia del arte granadino. El monasterio de San Jerónimo», en A. L. Cortés Peña y M. L. López-Guadalupe Muñoz (eds.). Estudios sobre iglesia y sociedad en Andalucía en la Edad Moderna: 504-520. Granada: Universidad.

Romero Torres, J. L. 2004. «La escultura y el patrimonio artístico de las colegiatas de Antequera», en La Real Colegiata de Antequera. Cinco siglos de historia, 1502-2003: 155-178. Antequera: Ayuntamiento.

Salas, X de. 1967. «Noticias de Granada recogidas por Ceán Bermúdez». Cuadernos de Arte y Literatura 1: 139-262.

Sánchez-Mesa Martín, D. 1971. Técnica de la escultura policromada granadina. Granada: Universidad.

Sánchez-Mesa Martín, D. 1994. El arte del Barroco: escultura, pintura y artes decorativas. Historia del Arte en Andalucía, vol. VII. Sevilla: Gever.

Sánchez-Mesa Martín, D. 2005. "La Escultura», en L. Gila Medina (coord.). El Libro de la catedral de Granada: vol. 1, 375-476. Granada: Cabildo Metropolitano.

Sigüenza, Fray J. de. 1605. Tercera parte de la Historia de la orden de San Jerónimo. Madrid: Imprenta Real.

Strauss, W. L. (ed.) 1978. The Illustrated Bartsch. New York: Abaris Books.

Valladar y Serrano, F. de P. 1906. La iglesia de San Jerónimo: estudio histórico. Granada: Paulino Ventura.

Ulierte Vázquez, M. a L. de 1994. "La arquitectura de los retablos», en El arte del Renacimiento. Urbanismo y arquitectura, Historia del Arte en Andalucía, vol. IV: 400-450. Sevilla: Gever. 